\title{
Enhancement the Fatigue Life of Floating Breakwater Mooring System Using Tuned Liquid Column Damper
}

\author{
Mostafa Shahrabia \\ Khosrow Bargi ${ }^{* *}$ (D) \\ a School of Civil Engineering, College of Engineering, Universtiy of Tehran, Tehran, Iran. E-mail: mshahrabi@ut.ac.ir, kbargi@ut.ac.ir \\ * Corresponding author \\ https://doi.org/10.1590/1679-78255692
}

\begin{abstract}
Safety is a key design criterion for floating structures. A high rate of mooring accidents has been reported over the past decades. Preventing mooring line failure is a key design objective for floating breakwater systems. The mooring system comprises sets of mooring lines anchored to the seabed. These components are exposed to highly cyclic nonlinear load fluctuations induced by an irregular wave climate during their service life. DNVGL-OS-E301 classifies the mooring lines for floating breakwaters as long-term elements that should be evaluated according to the fatigue limit state. Fatigue of mooring lines needs to be monitored and evaluated to warrant the station keeping and integrity of overall system. Applying an additional control device to a floating breakwater mitigates the structural response and hence mobilized tension in mooring system. The focus of present study was to examine the effect of an additional control device on fatigue life of mooring lines for floating breakwaters. To evaluate the effect of a control device on the fatigue behavior of mooring lines, a floating breakwater was simulated with a tuned liquid column damper (TLCD) attached. A time-dependent approach based on $\mathrm{S}-\mathrm{N}$ curves in conjunction with the Palmgren-Miner rule was employed to evaluate the mooring line fatigue. This paper presents a further parametric study focused on the effect of TLCD on fairlead point displacement, mobilized tension, damage rate, and fatigue life of mooring lines. The results showed that TLCD increased the fatigue life of mooring line and thus dramatically decreased the likelihood of the mooring system being damaged by fatigue. This would reduce the maintenance costs and increase the lifetime and operational safety of floating breakwater. In addition, the presented case study showed that failure probability of mooring lines against fatigue damage was also reduced and was acceptable for the safety factor defined in DNVGL-OS-E301. This proposed approach of applying a TLCD is a practical tool for designing the components of a floating breakwater more efficiently.
\end{abstract}

\section{Keywords}

floating breakwater (FB); tuned liquid column damper (TLCD); fatigue assessment; mooring system; S-N curves; structural control

\section{INTRODUCTION}

Growing maritime activity has led to the demand for a large amount of sheltered waters, where port facilities are protected from extreme environmental conditions. Traditionally, bottom-mounted breakwaters are constructed to provide a layer of support to ports. However, these structures are fundamentally limited by the challenging construction and negative environmental impact. As an alternative, floating breakwaters have drawn significant interest because of their advantages such as a lower construction cost, independence from the seabed soil condition, and absence of negative environmental impacts (Shahrabi and Bargi, 2013). A mooring system is used for the station keeping of these structures. 
Safety is a key design criterion for floating structures. A high rate of mooring accidents has been reported over the past decades. Kvitrud (2014) found that fatigue was the reason for one-third of 15 mooring line failures on the Norwegian continental shelf between 2010 and 2013. Ma et al. (2013) collected 23 failures of mooring lines and reported that three failures were due to the mooring material being weakened by fatigue. Thus, fatigue failure is an important limit state for mooring lines. A comprehensive fatigue assessment of the mooring system is necessary to propose viable actions for decreasing fatigue-induced failure and extending the fatigue life of mooring lines. The fatigue behavior of mooring lines depends heavily on a wide variety of factors like the material characteristics, stress range or magnitude, surface quality, and environmental conditions.

Several experimental and numerical studies have been carried out to understand the behavior of offshore mooring chains (e.g., De Laval, 1971; Van Helvoirt, 1982; Lereim, 1985). Research on the fatigue behavior of mooring lines has led to the release of $\mathrm{S}-\mathrm{N}$ curves and T-N curves by DNV GL and the American Petroleum Institute (API), respectively. Subsequently, numerous studies have been conducted on the fatigue analysis of mooring systems with S$\mathrm{N}$ or T-N curves (e.g., Horde and Moan, 1997; Lassen and Syvertsen, 1997). Gao and Moan (2007) proposed a frequency domain analysis for the fatigue assessment of mooring chains, which they validated through a comparison with a time domain simulation and the rainflow cycle counting method. Olagnon and Guede (2008) employed the rainflow cycle counting method and Gaussian process properties to propose theoretical formulas for estimating the cumulative damage during deployment periods and individual sea states. Thies et al. (2014) evaluated the fatigue damage to the mooring system of a floating marine energy convertor by applying the rainflow counting method with the Palmgren-Miner rule. They showed that any uncertainty in load cases would translate exponentially to the safety factor of the fatigue life. Therefore, an optimistic view is that any reduction in the load uncertainty will reap an exponential benefit in fatigue design. Hou et al. (2018) and Xu et al. (2014) analyzed the mooring system for a fish net cage to estimate the fatigue damage rate in both the time and frequency domains. Their results demonstrated that the fatigue damage was more sensitive to the wave height than the wave period. They also showed that increasing the analysis duration did not considerably change the results of the fatigue analysis. Xue et al. (2018) analyzed the fatigue behavior of the mooring system for a semisubmersible. They compared different fatigue evaluation methods and found that the $\mathrm{T}-\mathrm{N}$ curve approach is much more conservative than the $\mathrm{S}-\mathrm{N}$ curve approach. However, if appropriate safety factors suggested by API and DNV GL are applied, the fatigue life predictions by these approaches are comparable. DNVGL-OS-E301 recommends that the rainflow counting method can be the most accurate cycle identification technique.

In this study, the fatigue analysis for the mooring line of a floating breakwater is based on the $\mathrm{S}-\mathrm{N}$ curve approach. The fatigue damage is calculated in the time domain with the rainflow counting method. DNVGL-OS-E301 further recommends that the long-term environment should be represented by a number of discrete conditions. About 10-50 reference sea states are required. To meet the standard requirements and reduce load uncertainties, the long-term environmental conditions are represented by 30 short-term sea states.

Dampers are commonly implemented in buildings and bridges to mitigate the vibration amplitude and prevent discomfort, damage, or outright structural failure. The application of additional passive, active, and semi-active damping devices to protect offshore structures against the damaging effects of environmental loads has been studied. Because passive dampers have benefits like the lack of complex sensors or instrumental equipment, they have attracted considerable attention recently. The response mitigation by passive control devices of offshore structures under the action of environmental loads has been investigated by Colwell and Basu (2009), Lackner and Rotea (2011), Jaksic et al. (2015), and Ha and Cheong (2016). The tuned liquid column damper (TLCD) has features like compatibility with the surrounding environment and easy maintenance requirements and costs that make it an appropriate choice for offshore structures. Colwell and Basu (2009), Dezvareh et al. (2015), Bargi et al. (2016), and Hemmati et al. (2019) proved that the TLCD is capable of suppressing the response of fixed offshore wind turbines to wind and wave loadings. TLCDs were also found to greatly increase the fatigue life of structural elements. Lee and Juang (2012), Roderick (2012), Jaksic et al. (2015), and Coudurier et al. (2018) numerically studied the effect of a TLCD on the performance of floating structures. Although they successfully demonstrated the benefits of the TLCD for mitigating the response of the floating part of the system, they did not consider the effect of control devices on the fatigue life of mooring lines.

Therefore, the focus of the present study was to examine the effect of an additional control device on the fatigue life of mooring lines for floating breakwaters. The analysis was based on stress range distributions obtained from numerical simulations. A floating breakwater was excited for cases with and without a TLCD (i.e., FB-TLCD and FB, respectively) for comparison. The stress range is the most important parameter of fatigue life calculations. In general, reducing the stress range increases the fatigue life of mooring lines and decreases the likelihood of mooring system being damaged by fatigue. Simulation results demonstrated that including TLCD dramatically reduced peak mobilized 
tensile stress and stress range in mooring lines. Consequently, the likelihood of mooring system being damaged by fatigue decreased significantly, which would reduce maintenance costs and increase the lifetime and operational safety of the floating breakwater system. Therefore, the results proved that TLCD can be used as an efficient solution to improve the fatigue life of mooring lines.

The remainder of this paper is organized as follows. Section 2 briefly describes the model components and iterative coupling procedure used for the numerical simulations. Section 3 presents the wave-induced hydrodynamic forces on the floating breakwater, and the reactive responses of the TLCD and mooring system. Section 4 explains the general methodology employed to analyze the fatigue behavior of the mooring lines and predict the fatigue damage rate. Section 5 presents the results and discussion for the parametric study on the influence of the TLCD on the fatigue life of mooring chains. Finally, Section 6 presents the conclusions with implications for floating breakwaters that can be inferred from the results.

\section{FB-TLCD AND MOORING SYSTEM}

A moored floating breakwater was analyzed in the time domain. The system was investigated under the action of irregular waves in the open sea state. A new simulation tool was needed to apply a TLCD to a floating breakwater, which was achieved through the development of an iterative coupling procedure in ANSYS AQWA. Four independent TLCDs were incorporated into a floating breakwater in the ANSYS AQWA Hydrodynamic Diffraction module. The simulations were carried out by coupling the module with a FORTRAN subroutine. The developed iterative coupling procedure was applied to creating the joint FB-TLCD model. Numerous cases were modeled to investigate the effect of the TLCD on the fairlead displacement, mobilized tension, damage rate, and fatigue life of a mooring chain. To validate the original FB model, a moored FB was numerically simulated in ANSYS AQWA and compared with the works of Sannasiraj et al. (1998) and Loukogeorgaki and Angelides (2005). The model is briefly described here.

\subsection{Floating breakwater system}

The two main components of a floating breakwater are the floating body and mooring system. Various shapes for the floating body have been presented by Williams and Abul-Azm (1997), Williams et al. (2000), Gesraha (2006), Dong et al. (2008), Loukogeorgaki et al. (2014), and Ji et al. (2015). In order to fulfill the research objectives, a single rectangular section pontoon was selected as the floating body in this study. Fig. 1 shows the geometry of the floating breakwater.

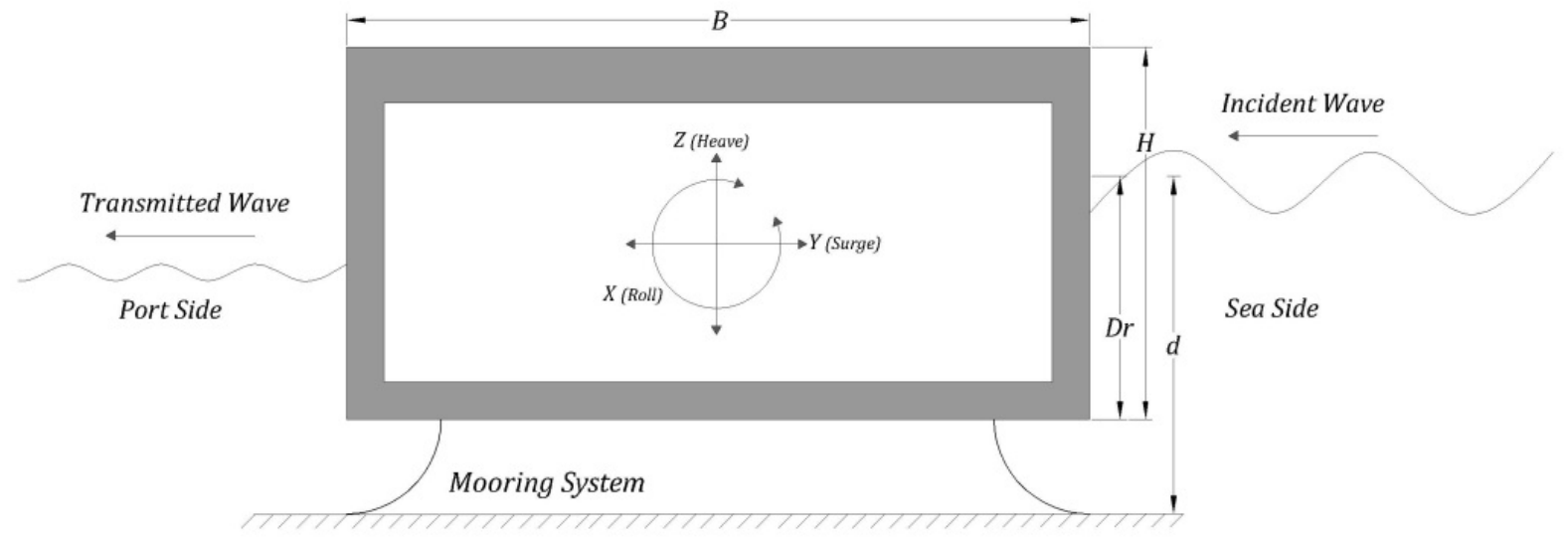

Figure 1 Schematic geometry of the moored floating breakwater.

The mooring system consisted of eight submerged stud link chains emanating from the four corners of the rectangular section pontoon. As shown in Fig. 2, the mooring lines were symmetrical in both the east-west and northsouth directions. Wave actions caused the floating body to deviate from its balanced position. The restoring forces of the mooring system returned the floating body to its balanced condition. The proposed method should allow the reactive forces and moments of the damping device to decrease the mobilized tension of the mooring chains. 


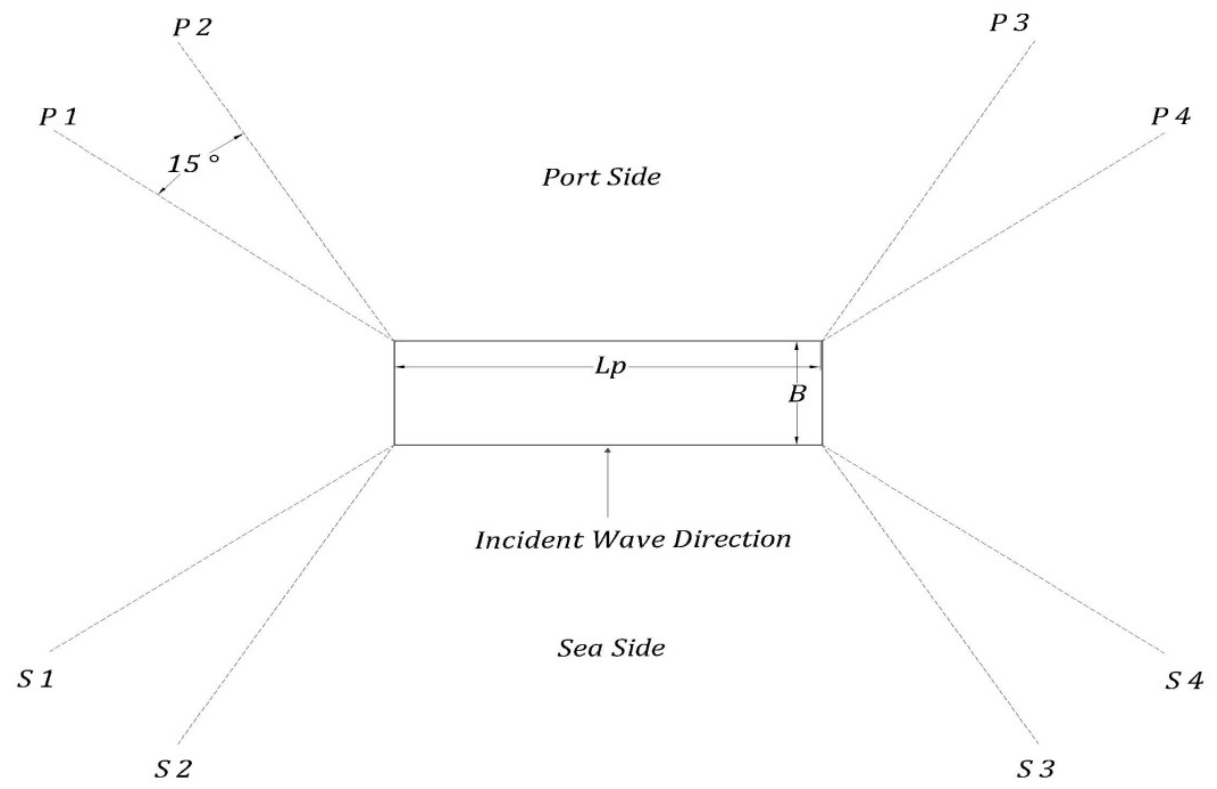

Figure 2 Layout of the mooring lines for the floating breakwater.

\subsection{Tuned Liquid Column Damper}

Various passive devices exist for structural control, including tuned mass dampers, tuned liquid dampers, TLCDs, and pendulum dampers. Factors such as the main structure specifications and surrounding environmental conditions should be considered when selecting the damping device. Sakai et al. (1989) proposed the TLCD as one of the most efficient passive damping systems. The TLCD has several benefits for offshore structures, such as compatibility with the main structure configuration and little need for auxiliary equipment, personnel, or power for operation and maintenance. These characteristics make it a practical and cost-effective solution for application in offshore structures. As shown in Fig. 3, this U-shaped device comprises two vertical and one horizontal piping systems. The performance of the TLCD depends on the displacement of liquid residing in its piping system. Excessive motions of the main structure are significantly suppressed by the gravitational restoring forces and moments acting on the displaced liquid in the horizontal and vertical columns. Lee et al. (2006), Roderick (2012), Mousavi et al. (2012), and Dezvareh et al. (2015) proved the effectiveness of the TLCD at mitigating the responses of fixed or floating offshore platforms. However, the influence of the TLCD on the fatigue behavior of mooring lines for floating structures has not been studied. This paper is the first to present the implementation of a damping device in a floating breakwater to enhance the fatigue life of its mooring system.

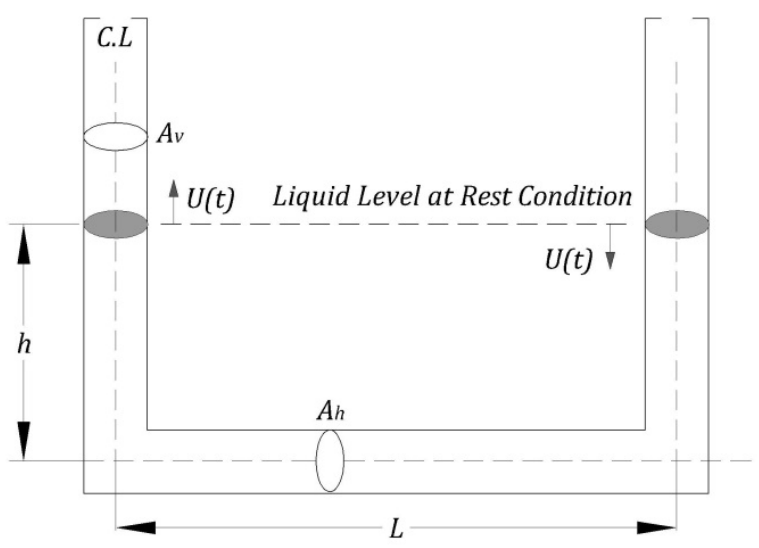

Figure 3 Layout of tuned liquid column damper.

The rigid symmetrical piping system of the TLCD was embedded inside the void space of the rectangular pontoon to form a rigid system. This placement isolated the substructure from the direct influence of environmental loads. Fig. 4 shows a simple schematic of the TLCD configuration for the floating breakwater. The motion of the floating pontoon 
led to fluid movement inside the TLCD pipes, which generated reactive forces and moments at its contact point with the floating body. The TLCD had a similar configuration in the side-side direction.

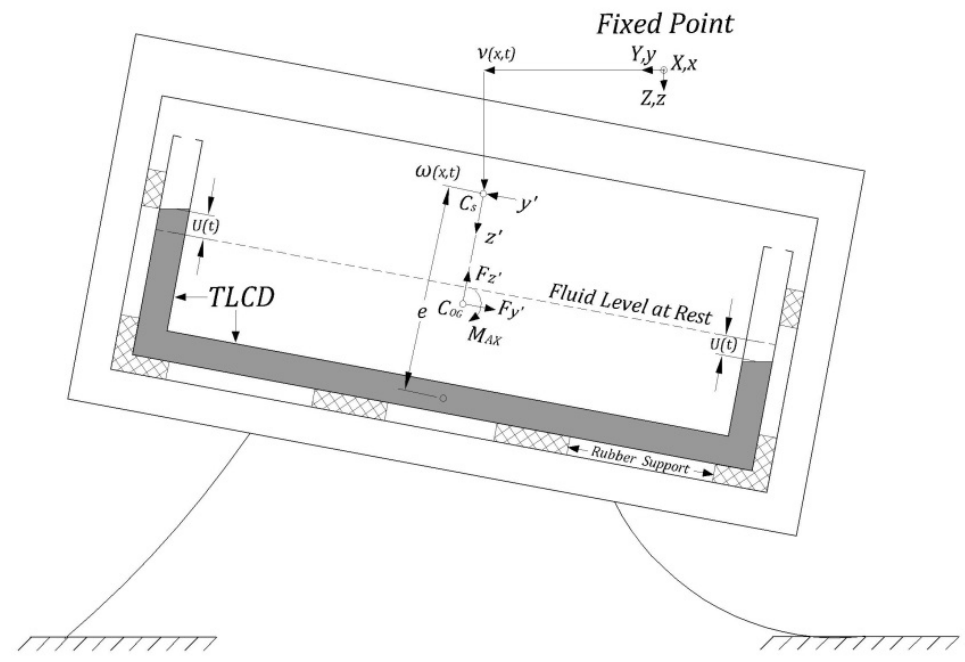

Figure 4 Schematic of tuned liquid column damper in floating breakwater.

\subsection{Iterative Coupling Procedure}

In order to model a TLCD system in a floating breakwater, the additional dynamics of the damping system need to be coupled with the original motions of the floating breakwater. This can be implemented with an external model of the TLCD coupled to the floating breakwater via ANSYS AQWA. One of the features of ANSYS is the ability to include a user-defined external force algorithm via a dynamic link library (DLL). This algorithm was employed to calculate the external reaction forces and moments based on the time, position, velocity, and acceleration of the floating breakwater. Thus, the TLCD and moored floating breakwater were coupled with the iterative coupling procedure as shown in Fig. 5. For this approach, the geometry of the floating pontoon, physical characteristics of the TLCD, and environmental conditions were used as the simulation inputs.

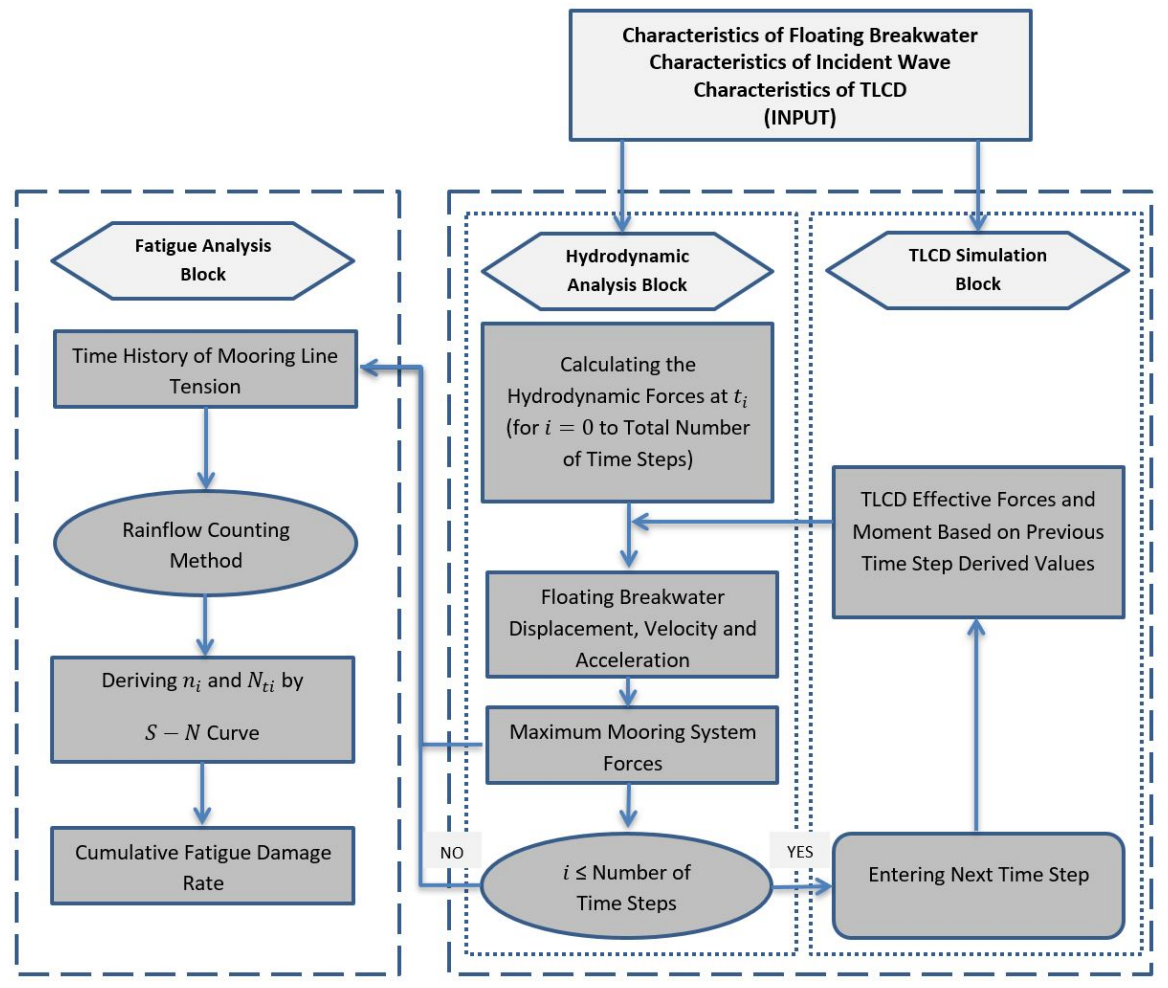

Figure 5 Iterative coupling procedure for creating TLCD-FB model. 
Fig. 6 shows the numerical model of the moored floating breakwater created with the ANSYS AQWA Hydrodynamic Diffraction module. In the first iteration cycle, this structure was subjected to the hydrodynamic forces, and the displacements, velocities, and accelerations of the floating body were then calculated. These parameters were then exported to the governing equations of the TLCD. The theoretical equations of TLCD are extensively presented in the following section. The imported data were used to calculate the reactive forces and moments transmitted from the damper to the floating breakwater, which were exported to the model of the moored floating breakwater to start the second iteration cycle. These values were considered to be external forces and moments acting on the center of body of the floating body. The system properties at the end of one cycle were then employed as the starting conditions for the next, and a time history for the motions of the floating breakwater was then constructed. The procedure was repeated until the end of the modeling time was reached.

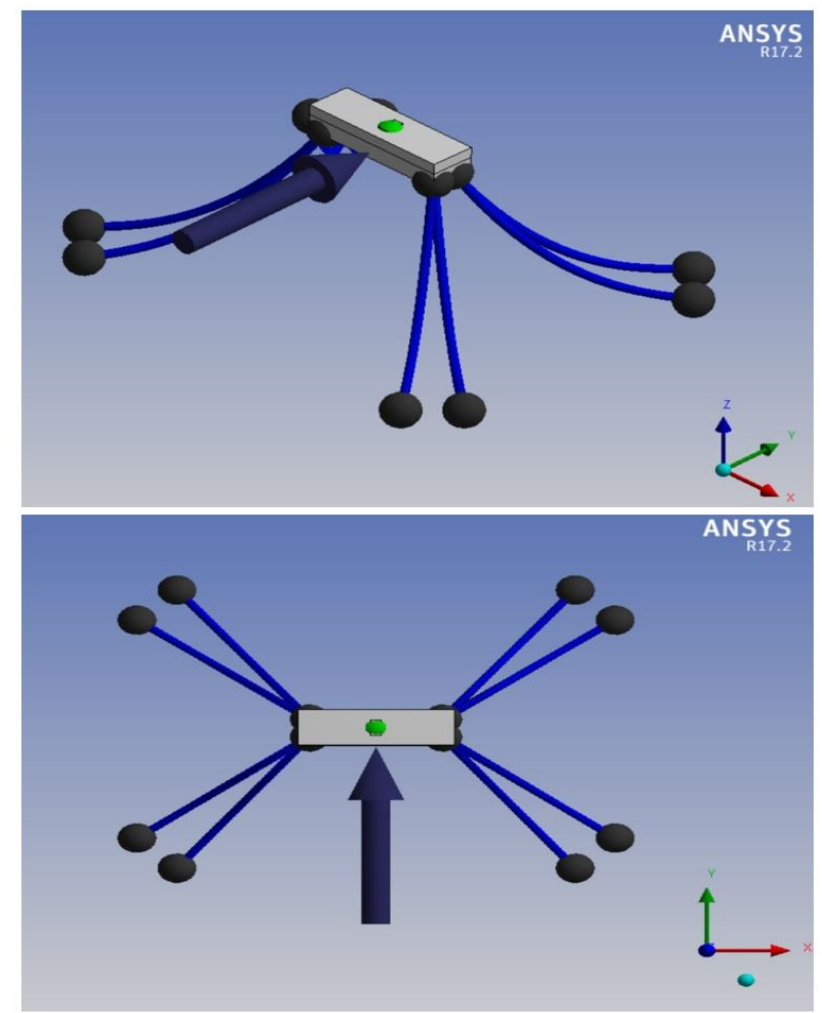

Figure 6 Model of moored floating breakwater in ANSYS AQWA.

\subsection{Validation}

The numerical model of the moored floating breakwater was validated according to the physical model tests of Sannasiraj et al. (1998) and numerical simulation results of Loukogeorgaki and Angelides (2005). The model consisted of a single pontoon subjected to the action of incident waves. The length, width, and draft of the rectangular pontoon were $3.78,0.4$, and $0.1 \mathrm{~m}$, respectively. To maintain the position of the model, four mooring lines were modeled at locations $0.15 \mathrm{~m}$ apart from the bottom surface of the floating body with a unit weight of $1.25 \mathrm{~N} / \mathrm{m}$ in air. The total mass of the model was $150.5 \mathrm{~kg}$, and the mass moments of inertia in the $\mathrm{x}, \mathrm{y}$, and $z$ directions were 188, 5.33, and $189.8 \mathrm{~kg} \mathrm{~m} 2$, respectively.

Fig. 7 compares the computed values for the response amplitude operator (RAO) in the surge, heave, and roll motions as a function of the normalized wave frequency with the results of Sannasiraj et al. (1998) and Loukogeorgaki and Angelides (2005). A good level of agreement between the results was observed. The comparison with the two other studies demonstrated that the results of the present model were close to the experimental test results. The strong coupling of the surge and heave responses was the main reason for the increased surge response at $\left(\omega^{\wedge} 2\right.$ $\mathrm{B} / 2 \mathrm{~g}=0.4$. The best agreement between the results was for the roll RAO. The derived responses were sufficiently close to those achieved by Sannasiraj et al. (1998) and Loukogeorgaki and Angelides (2005). The trends for the measured RAOs in this study and the reference studies were similar for the roll. There was only a negligible difference with the responses near the natural frequency of the roll. 

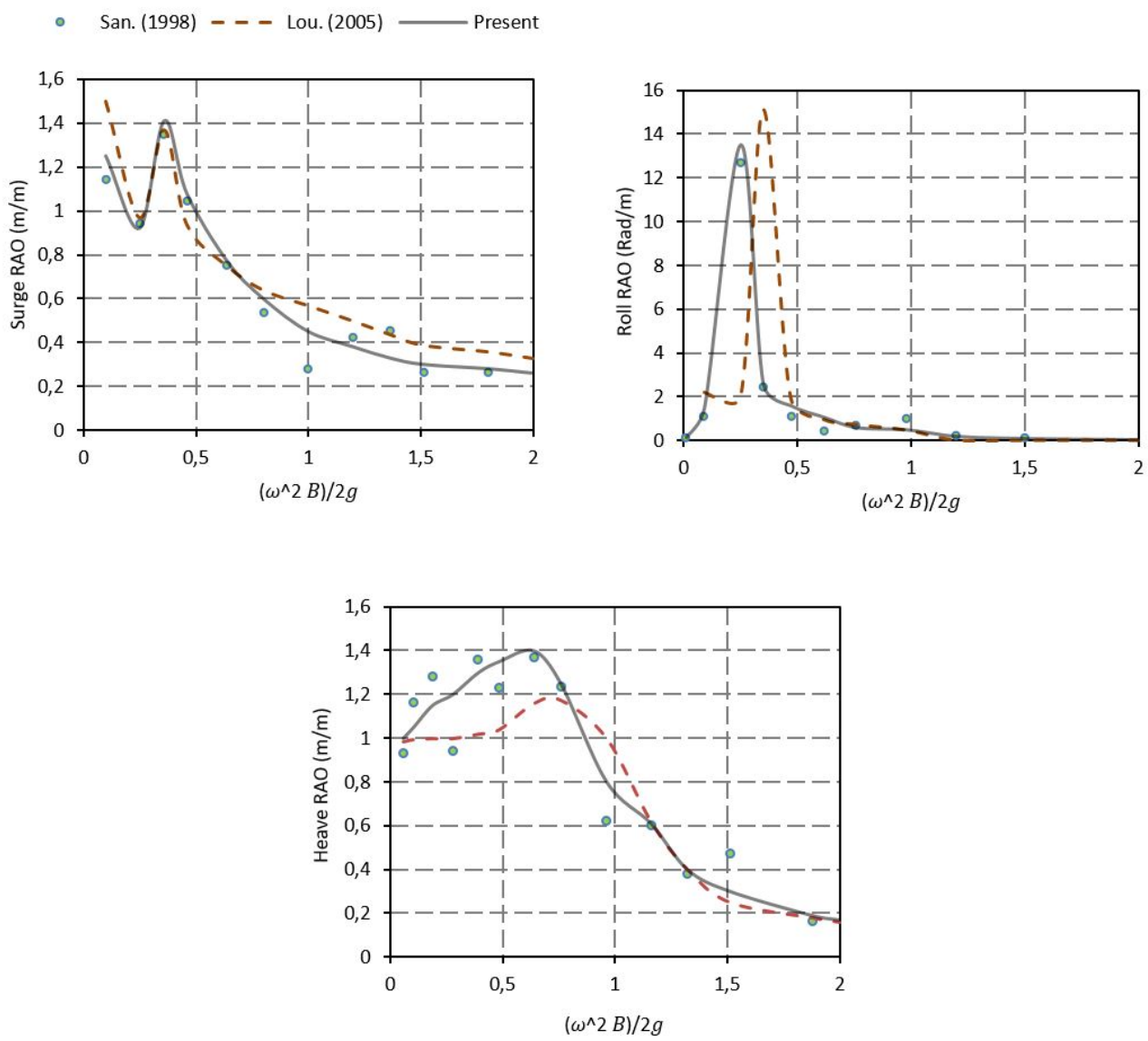

Figure 7 Comparison of computed RAO as a function of $\frac{\omega^{2} B}{2 g}$.

\section{GOVERNING EQUATIONS}

\subsection{Description of Wave Field}

Fig. 8 shows the single rectangular pontoon floating breakwater installed in the Persian Gulf that was analyzed in this study. The Persian Gulf is a large semi-enclosed sea at the northwest end of the Indian Ocean. The JONSWAP spectrum was formulated for a developing sea state in a fetch limited situation. The Persian Gulf specifications are in accordance with this spectrum fundamental assumption. Thus, the JONSWAP spectrum was applied here as the input spectrum. In Eq. 1, $\gamma$ is the peak enhancement factor, $\sigma$ is the peak shape factor, $g$ is the acceleration of gravity, $f$ is the wave frequency, and $f \_p$ is the spectral dominant frequency.

$\mathrm{S}(\mathrm{f})=\frac{\alpha \mathrm{g}^{2}}{(2 \pi)^{4} \mathrm{f}^{5}} \exp \left[-1.25\left(\frac{\mathrm{f}}{\mathrm{f}_{\mathrm{p}}}\right)^{-4}\right] \gamma^{\exp \left(\frac{(\mathrm{f}-\mathrm{f} \mathrm{p})^{2}}{-2 \sigma^{2} \mathrm{f}^{2}}\right)}$

The JONSWAP project wave data were used to derive the values of constants $\sigma$ and $\alpha$. In Eq. 3, $H \_s$ is the significant wave height.

$\sigma=\left\{\begin{array}{l}0.07 \text { for } \mathrm{f}<\mathrm{f}_{\mathrm{p}} \\ 0.09 \text { for } \mathrm{f} \geq \mathrm{f}_{\mathrm{p}}\end{array}\right.$

$\alpha=4.5 \mathrm{H}_{\mathrm{s}}^{2} \mathrm{f}_{\mathrm{p}}^{4}$

The superposition of multiple monochromatic linear waves is employed to calculate the horizontal and vertical velocity of water particles for random waves, as follows: 


$$
\begin{aligned}
& u(x, z, t)=\sum_{i=1}^{n} a_{i} \cdot 2 \pi f_{i} \frac{\cosh \left(k_{i}(z+h)\right)}{\sinh \left(k_{i} h\right)} \cos \left(k_{i} x-2 \pi f_{i} t+\varepsilon_{i}\right) \\
& w(x, z, t)=\sum_{i=1}^{n} a_{i} \cdot 2 \pi f_{i} \frac{\sinh \left(k_{i}(z+h)\right)}{\sinh \left(k_{i} h\right)} \sin \left(k_{i} x-2 \pi f_{i} t+\varepsilon_{i}\right)
\end{aligned}
$$

In Eq. 4 and 5, $u$ and $w$ are the horizontal and vertical velocities, respectively, $a$ is the wave amplitude, and $\mathrm{k}$ is the angular wave number.

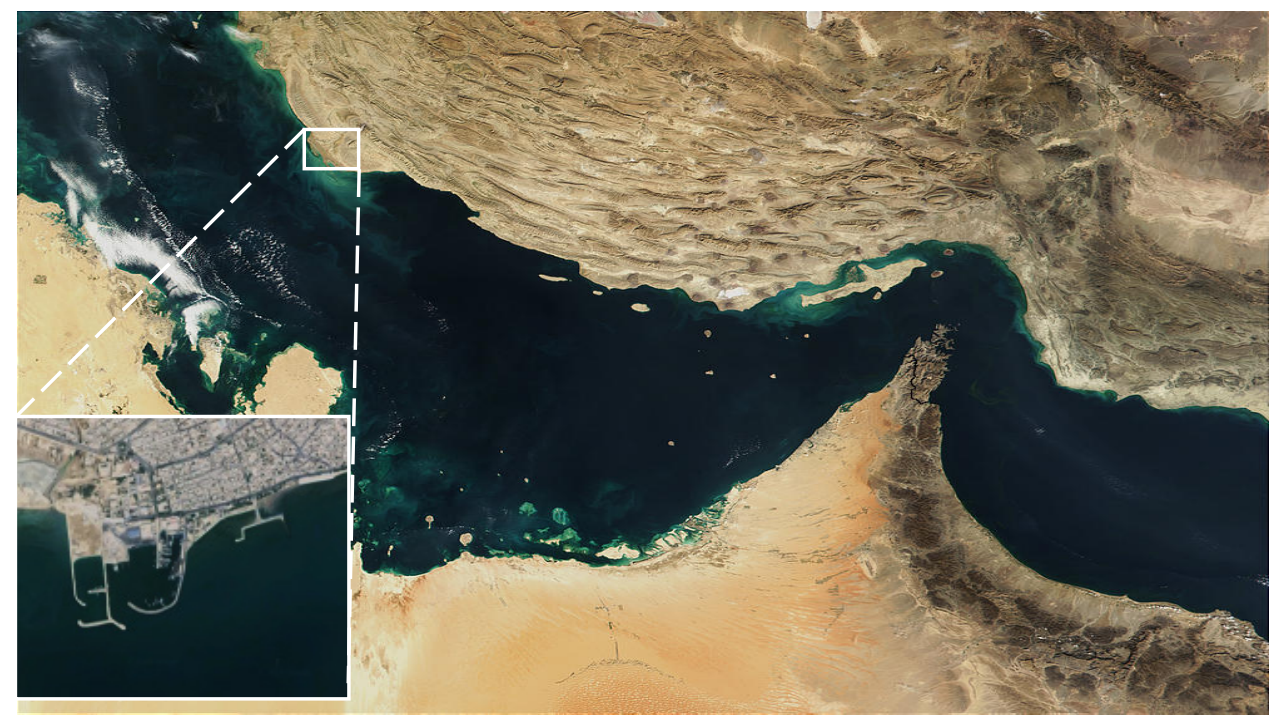

Figure 8 The study area.

According to DNVGL-OS-E301, the long-term environment should be represented by a number of discrete conditions. Each condition consists of a reference direction and reference sea state characterized by a significant wave height, peak period, and the probability of occurrence. About 10-50 reference sea states are required. In this study, the long-term environmental conditions for the Persian Gulf over 1 year were represented by 30 short-term sea states, which were used for dynamic mooring analysis in the time domain to obtain the tension response. Table 1 presents the specifications of the short-term sea states. Each condition consisted of a reference sea state characterized by a significant wave height, peak wave period, and the occurrence probability. The waves were assumed to propagate in the normal direction to the floating breakwater at all times.

\begin{tabular}{|c|c|c|c|c|c|c|c|}
\hline No. & $H_{s}(\boldsymbol{m})$ & $T_{p}(s)$ & $\boldsymbol{P}(\%)$ & No. & $H_{s}(\boldsymbol{m})$ & $T_{p}(s)$ & $\boldsymbol{P}(\%)$ \\
\hline 1 & 0.5 & 3 & 7.5 & 16 & 2.0 & 5 & 9.3 \\
\hline 2 & 1.0 & 3 & 6.5 & 17 & 2.5 & 5 & 0.2 \\
\hline 3 & 1.5 & 3 & 2.8 & 18 & 3.0 & 5 & 0.1 \\
\hline 4 & 2.0 & 3 & 1.1 & 19 & 0.5 & 6 & 2.1 \\
\hline 5 & 2.5 & 3 & 0.5 & 20 & 1.0 & 6 & 5.5 \\
\hline 6 & 3.0 & 3 & 0.1 & 21 & 1.5 & 6 & 5.3 \\
\hline 7 & 0.5 & 4 & 10.8 & 22 & 2.0 & 6 & 2.3 \\
\hline 8 & 1.0 & 4 & 4.0 & 23 & 2.5 & 6 & 0.1 \\
\hline 9 & 1.5 & 4 & 2.6 & 24 & 3.0 & 6 & 0.4 \\
\hline 10 & 2.0 & 4 & 1.5 & 25 & 0.5 & 7 & 3.2 \\
\hline 11 & 2.5 & 4 & 0.8 & 26 & 1.0 & 7 & 2.6 \\
\hline 12 & 3.0 & 4 & 0.1 & 27 & 1.5 & 7 & 2.1 \\
\hline 13 & 0.5 & 5 & 2.5 & 28 & 2.0 & 7 & 2.3 \\
\hline 14 & 1.0 & 5 & 6.7 & 29 & 2.5 & 7 & 1.9 \\
\hline 15 & 1.5 & 5 & 15.2 & 30 & 3.0 & 7 & 0.3 \\
\hline
\end{tabular}

Table 1 Environmental conditions used in the fatigue analysis 


\subsection{Hydrodynamic Forces}

The hydrodynamic forces on the floating breakwater were derived in ANSYS AQWA with the potential flow theory. A detailed explanation of this method is outside the scope of this paper. Although specific details on the use of the potential flow theory in ANSYS AQWA is given in the ANSYS theory manual (Ansys V.17.2, 2016), the hydrodynamic analysis is briefly explained here.

The hydrodynamic analysis of a floating breakwater subjected to irregular waves was carried out to obtain the dynamic response of the floating body and time history of the tensile stress at the mooring lines. The potential flow theory and three-dimensional panel method were used to derive the hydrodynamic loads. ANSYS AQWA employs a hybrid method to model large-volume floating structures like a floating breakwater. The first-order potential flow theory is employed for radiation and diffraction analysis. The hydrodynamic pressure distribution is calculated with the linearized Bernoulli equation. In Eq. 6, $\rho$ is the sea water density and $\omega$ is the angular frequency of the wave.

$\mathrm{p}^{(1)}=-\rho \frac{\partial \varphi(\overrightarrow{\mathrm{x}}, \mathrm{t})}{\partial \mathrm{t}}=\mathrm{i} \omega \rho \varphi(\overrightarrow{\mathrm{x}}) \mathrm{e}^{-\mathrm{i} \omega \mathrm{t}}$

Then, the first order hydrodynamic force on floating body is calculated by integrating the hydrodynamic pressure over the wetted surface of the body, $\mathrm{S}_{0}$, as follows:

$\mathrm{F}_{\mathrm{Ij}}=-\mathrm{i} \omega \rho\left(\int \varphi_{\mathrm{I}}(\overrightarrow{\mathrm{x}}) \mathrm{n}_{\mathrm{j}} \mathrm{ds}\right)_{\mathrm{s}_{0}}$

$\mathrm{F}_{\mathrm{Dj}}=-\mathrm{i} \omega \rho\left(\int \varphi_{\mathrm{D}}(\overrightarrow{\mathrm{x}}) \mathrm{n}_{\mathrm{j}} \mathrm{ds}\right)_{\mathrm{s}_{0}}$

$\mathrm{F}_{\mathrm{Rjk}}=-\mathrm{i} \omega \rho\left(\int \varphi_{\mathrm{Rj}}(\overrightarrow{\mathrm{x}}) \mathrm{n}_{\mathrm{j}} \mathrm{ds}\right)_{\mathrm{s}_{0}}$

In Eqs. 7-9, $F_{I j}$ is the incident wave force, $F_{D j}$ is the diffracted wave force, and $F_{R j k}$ is the radiation force induced by the kth unit amplitude motions of the floating body. In the above equations, $\varphi_{\mathrm{I}}$ is the first-order incident wave potential with the unit wave amplitude, $\varphi_{\mathrm{D}}$ is the corresponding diffracted wave potential, and $\varphi_{\mathrm{Rj}}$ is the radiated wave potential due to the jth motion of the floating body with the unit motion amplitude. To solve Eqs. 7-9, the HessSmith constant panel method is employed. The mean wetted surface of the floating body is divided into quadrilateral panels. The potential and source strength within each panel are assumed to be constant. Thus, the corresponding average values over each panel surface are taken for the simulation.

\subsection{Mooring System Forces}

The mooring system comprises sets of mooring lines anchored to the seabed. These components are exposed to highly cyclic nonlinear load fluctuations induced by an irregular wave climate during their service life. DNVGL-OS-E301 classifies the mooring lines for floating breakwaters as long-term elements that should be evaluated according to the fatigue limit state (FLS). The most accurate approach to estimating the fatigue is a combination of the S-N curve approach and the rainflow cycle counting method. These methods are extensively described in the following section. The time history of the tensile stress is a prerequisite for the fatigue assessment and predicting the fatigue life of the mooring lines.

The mooring system is analyzed according to the mutual interaction between the mooring lines and motions of the floating body. Each mooring line is discretized into a number of Morison-type elements; Fig. 9 shows the configuration. The total response of the mooring line $\mathrm{T}$ is a combination of the low-frequency tension $\mathrm{T}_{\mathrm{LF}}$ and wave frequency tension $\mathrm{T}_{\mathrm{WF}}$ :

$\mathrm{T}=\mathrm{T}_{\mathrm{LF}}+\mathrm{T}_{\mathrm{WF}}$

The quasi-static method is employed to derive the low-frequency tension induced by the floating body offset. For a catenary mooring line with zero slope at the connection point of the anchor on the seabed, the mooring line responses on the local axis system are expressed as follows:

$\mathrm{H}_{2}=\mathrm{AE}\left(\sqrt{\left(\frac{\mathrm{T}_{2}}{\mathrm{AE}}+1\right)^{2}-\frac{2 \mathrm{wZ}}{\mathrm{AE}}}-1\right)$ 
$\mathrm{X}_{2}=\mathrm{H}_{2}\left(\frac{1}{\mathrm{w}} \sinh ^{-1}\left(\frac{\mathrm{wL}}{\mathrm{H}_{2}}\right)+\frac{\mathrm{L}}{\mathrm{AE}}\right)$

$\mathrm{V}_{2}=\mathrm{wL}$

$\mathrm{T}_{2}=\sqrt{\mathrm{H}_{2}^{2}+\mathrm{V}_{2}^{2}}$

In Eqs. 11-14, A is the cross-sectional area of the mooring line, $\mathrm{E}$ is Young's modulus, $\mathrm{L}$ is the total unstretched length of the mooring line, and $\mathrm{w}$ is the submerged weight per unit length of the mooring line. As shown in Fig. 9, the local $\mathrm{x}$-axis is a projection of the vector joining the anchor point and fairlead attachment point on the seabed, and the z-axis pointed vertically upwards.

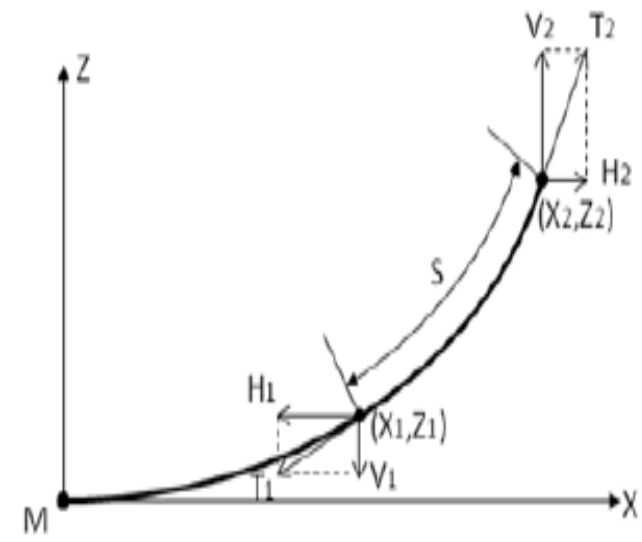

Figure 9 Geometry of mooring lines.

When the unstretched length of the mooring line from the fairlead position is $S$, the position of the bottom end of this segment is given by:

$\mathrm{X}_{1}=\frac{\mathrm{H}_{2}}{\mathrm{w}} \ln \frac{\mathrm{V}_{2}+\mathrm{T}_{2}}{\mathrm{~V}_{1}+\mathrm{T}_{1}}+\frac{\mathrm{H}_{2} \mathrm{~S}}{\mathrm{AE}}$

$Y_{1}=S\left(V_{1}+V_{2}\right)\left(\frac{1}{T_{1}+T_{2}}+\frac{1}{2 A E}\right)$

Then, the horizontal and vertical components of the low-frequency tension at each cross-section of the mooring line e.g., at (X1, Y1) as shown at Fig. 9, is given by:

$\mathrm{V}_{1}=\mathrm{V}_{2}-\mathrm{wS}$

$\mathrm{T}_{1}=\sqrt{\mathrm{H}_{1}^{2}+\mathrm{V}_{1}^{2}}$

The mooring tension caused by the wave frequency motions is derived by a dynamic method:

$\mathrm{M} \ddot{\mathrm{X}}+\mathrm{KX}=\mathrm{F}_{\text {static }}+\mathrm{F}_{\mathrm{WF}}+\mathrm{T}_{\mathrm{WF}}$

In Eq. 19, $\mathrm{M}$ and $\mathrm{K}$ are the assembled total mass and stiffness matrices, respectively; $\mathrm{F}_{\text {static }}$ is the static load, and $\mathrm{T}_{\mathrm{WF}}$ is the wave-induced tension from the mooring system. The hydrodynamic force $\mathrm{F}_{\mathrm{WF}}$, on a mooring element consists of the buoyant force $F_{b}$, drag force $F_{d}$, and added mass force:

$F_{W F}=F_{b}+F_{d}-M_{a}\left[\vec{a}_{j}, \vec{a}_{j+1}\right]^{T}$

In Eq. 20, $\mathrm{M}_{\mathrm{a}}$ is the added mass matrix of mooring line and $\overrightarrow{\mathrm{a}}_{\mathrm{j}}$ is the acceleration of the mooring line at the node $\mathrm{j}$. 


\subsection{TLCD Equations}

As illustrated in Fig. 3, the TLCD comprises a U-shaped pipe that is partially filled with fluid, and the liquid mass is given by $\mathrm{m}_{\mathrm{f}}$. The fluid relative motion $\mathrm{U}(\mathrm{t})$ describes the displacement of its interface to the atmosphere, which is equivalent to the change in elevation of the liquid columns. The design parameters of the TLCD are shown in Figs. 3 and 4. Reiterer and Ziegler (2006) derived the equation of fluid motion inside horizontal and vertical columns by applying the modified Bernoulli equation along the incompressible flow streamline:

$\ddot{U}+\delta_{\mathrm{L}}|\dot{U}| \dot{U}+\omega_{A}^{2}\left[1-\mathrm{k}_{1} \frac{\mathrm{a}_{\mathrm{z}^{\prime}}}{\mathrm{H} \omega_{\mathrm{A}}^{2}}-\mathrm{k}_{2} \frac{\dot{\mathrm{v}}^{2}}{\omega_{\mathrm{A}}^{2}}\right] \mathrm{U}=\mathrm{k}\left[\mathrm{a}_{\mathrm{y}^{\prime}}-\mathrm{g \vartheta}\right]-\mathrm{k}_{1} \frac{\mathrm{B}}{2} \ddot{\vartheta}$

In Eq. 21, $\delta_{\mathrm{L}}$ is the head loss coefficient and $\omega_{\mathrm{A}}$ is the un-damped circular natural frequency of the TLCD. The geometrica coefficients used in Eq. 21 are defined as follows:

$\mathrm{k}_{1}=\frac{2 \mathrm{~h}}{\mathrm{~L}_{\mathrm{eff}}}$

$\mathrm{k}_{2}=\frac{\mathrm{L}+2 \mathrm{~h}}{\mathrm{~L}_{\mathrm{eff}}}$

$\mathrm{k}=\frac{\mathrm{L}}{\mathrm{L}_{\mathrm{eff}}}$

$L_{\text {eff }}=2 h+\frac{A_{v}}{A_{h}} L$

In Eqs. 22-24, $\mathrm{h}$ is the length of the liquid column in the vertical pipe section at rest, $\mathrm{L}$ is the horizontal length of the liquid column, $A_{v}$ is the vertical cross-sectional area of the liquid column, and $A_{h}$ is the horizontal cross-sectional area of the liquid column. The absolute acceleration of the TLCD at its reference point $A\left(y^{\prime}, z^{\prime}\right)$ is derived as follows:

$\overrightarrow{\mathrm{a}_{\mathrm{A}}}=\ddot{\mathrm{e}} \overrightarrow{\mathrm{y}}+\ddot{\omega} \overrightarrow{\mathrm{z}_{\mathrm{z}}}-\mathrm{dA}\left(\ddot{\vartheta} \overrightarrow{\mathrm{e}^{\prime}}+\dot{\vartheta}^{2} \overrightarrow{\mathrm{e}_{\mathrm{z}^{\prime}}}\right)$

In Eq. 26, $\ddot{v}, \ddot{\omega}$ and $\ddot{\vartheta}$ are the absolute translational and rotational accelerations of the main structure around its center of gravity. With a normal incident wave, the response of the damping device to the floating breakwater motion is represented by two perpendicular forces and a moment. These effective parameters are applied at an imaginary reference point of the TCLD. With the momentum conservation principle and if the point of application is shifted from the reference point to the center of gravity of the floating body, the reactive forces and moments transmitted from the damper to the floating breakwater are calculated as follows:

$\mathrm{F}_{\mathrm{y}^{\prime}}=\mathrm{m}_{\mathrm{f}}\left[\mathrm{a}_{\mathrm{y}^{\prime}}-\frac{\mathrm{L}}{\mathrm{L}_{1}}\left(\ddot{\mathrm{u}}-\mathrm{u} \dot{\vartheta}^{2}\right)+\frac{1}{\mathrm{~L}_{1}}\left(\left(\mathrm{~h}^{2}+\mathrm{u}^{2}\right) \ddot{\vartheta}+4 u \dot{u} \dot{\vartheta}\right)\right]$

$\mathrm{F}_{\mathrm{z}^{\prime}}=\mathrm{m}_{\mathrm{f}}\left[\mathrm{a}_{\mathrm{z}^{\prime}}-\frac{\mathrm{L}}{\mathrm{L}_{1}}(\mathrm{u} \ddot{\vartheta}+2 \dot{\mathrm{u}} \dot{\vartheta})+\frac{1}{\mathrm{~L}_{1}}\left(\left(\mathrm{~h}^{2}+\mathrm{u}^{2}\right) \dot{\vartheta}^{2}-2\left(\dot{\mathrm{u}}^{2}+\mathrm{u} \ddot{\mathrm{u}}\right)\right]\right.$

$\mathrm{M}_{\mathrm{Ax}}=\mathrm{m}_{\mathrm{f}}\left\{-\mathrm{a}_{\mathrm{y}^{\prime}} \mathrm{d}+\frac{1}{\mathrm{~L}_{1}}\left[\mathrm{Lh} \ddot{\mathrm{u}}-4 \mathrm{u} \dot{\mathrm{\vartheta}} \dot{\mathrm{\vartheta}} \mathrm{d}+\left(\mathrm{h}^{2}+\mathrm{u}^{2}\right)\left[\mathrm{a}_{\mathrm{y}^{\prime}}+\mathrm{g} \vartheta-\mathrm{d} \ddot{\vartheta}\right]\right]+\frac{2 \mathrm{~h}}{\mathrm{~L}_{1}}\left[\mathrm{u}^{2} \ddot{\vartheta}+2 u \dot{u} \dot{\vartheta}\right]+\bar{k} h^{2} \ddot{\vartheta}\right\}$

The values obtained by Eqs. 27-29 are considered to be the external forces and moment acting on the center of gravity of the floating body. The following geometric coefficient is used in Eqs. 27-29:

$\overline{\mathrm{k}}=\frac{2 \mathrm{~h}}{3 \mathrm{~L}_{1}}\left(1+\frac{3 \mathrm{~L}^{2}}{4 \mathrm{~h}^{2}}+\frac{\mathrm{A}_{\mathrm{h}}}{\mathrm{A}_{\mathrm{v}}} \frac{\mathrm{L}^{3}}{8 \mathrm{~h}^{3}}\right)$

\section{FATIGUE ANALYSIS}

Fatigue failure is a well-known failure mechanism for materials and components exposed to fluctuating load conditions (Schutz, 1996). It occurs in mooring lines because of the response to cyclic tension. If a mooring line fails, the 
floating body loses its station and can severely damage the surrounding environment and port facilities. Thus, predicting the fatigue service life of mooring lines is a key design objective for floating breakwater system to prevent potential failure.

Predicting the fatigue service life of a mooring line is difficult. The fatigue behavior is influenced by many variables such as the mean stress level, geometric characteristics, and metallurgical variables. The tensile fatigue behavior of mooring lines can be evaluated with stress-life cumulative damage models or fatigue crack growth models. The former method estimates the fatigue life with the Palmgren-Miner rule in conjunction with $\mathrm{S}-\mathrm{N}$ or $\mathrm{T}-\mathrm{N}$ curves and is based on the assumption of linear damage accumulation. The second methodology is based on fracture mechanics and evaluates the fatigue-induced fracture of mechanical elements under cyclic loads. Nijssen (2006) proved that the computational effort of the fracture mechanics approach is not justified by the small advantage over the Palmgren-Miner rule approach. Xue et al. (2018) concluded that, if appropriate safety factors as suggested by DNVGL-OS-E301 are considered with the S-N curve method, the two methodologies are generally comparable in terms of predicting the fatigue life. In the present study, the $\mathrm{S}-\mathrm{N}$ curve approach was employed to estimate the fatigue damage rate and predict the fatigue life of mooring lines.

\subsection{S-N Curve Approach}

To estimate the fatigue life, the long-term cyclic loading of a mooring line is compared with the resistance of this component to fatigue damage. The time history of the mooring line tension, appropriate S-N curve, and damage accumulation hypothesis are the three fundamental pieces of information required for the S-N curve approach. The time domain variations in the mobilized tension were obtained from the numerical modeling results. These values were employed as input data for the selected fatigue evaluation approach.

The stud chain is commonly used as a mooring line for floating breakwaters to hold it in a relatively stable position. DNVGL-OS-E301 presents the fatigue data of stud chain mooring lines from several testing programs, which are plotted in Fig. 10. These curves plot the nominal stress ranges versus the number of cycles to the failure. In general, the $\mathrm{S}-\mathrm{N}$ curve is given:

$\log \left(N_{t}\right)=\log (\bar{a})-m \log (\Delta \sigma)$

Where $\mathrm{N}_{\mathrm{t}}$ is the number of stress cycles to failure, $\Delta \sigma$ is the nominal stress range in MPa, $\overline{\mathrm{a}}$ is the intercept parameter of the S- $\mathrm{N}$ curve, and $\mathrm{m}$ is the slope of stress range. Because the $\mathrm{S}-\mathrm{N}$ curve is given in terms of the nominal stress range, this parameter can be calculated by:

$\sigma_{\text {nominal }}=\frac{\mathrm{T}}{\mathrm{A}}$

In Eq. $32, \sigma_{\text {nominal }}$ is the nominal stress in MPa, $\mathrm{T}$ is the measured mooring force based on Eq. 10 in $\mathrm{N}$ and $\mathrm{A}$ is the cross sectional area of mooring line in $\mathrm{mm}^{2}$.

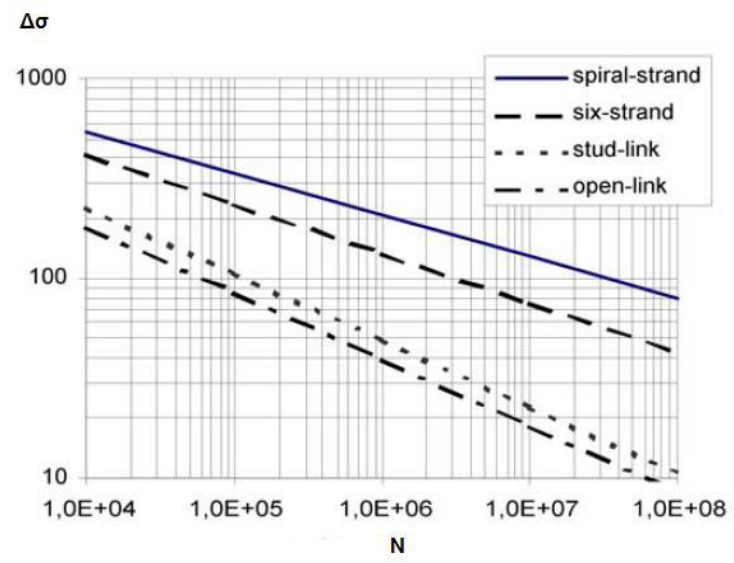

Figure 10 S-N curves for mooring lines (DNVGL-OS-E301).

The time histories of tension for different short-term sea states are used to derive the stress ranges and their corresponding number of cycles. The stress history of a mooring line is random; thus, the counting method is needed to quantify the number of cycles and stress ranges. DNVGL-OS-E301 introduced the rainflow counting method as the most 
accurate cycle identification technique. Therefore, this method was applied in the present study to obtain the above parameters. This methodology allows the damage accumulation hypothesis to be applied to estimating the fatigue damage rate and predicting the fatigue life of mooring lines subjected to complex random loads.

\subsection{Palmgren-Miner Rule}

Under normal operating conditions, floating breakwaters are subjected to nonlinear wave actions across their service life. Consequently, the mooring system is subjected to alternating stress amplitudes. The Palmgren-Miner rule can be used to estimate the cumulative fatigue damage rate based on a single slope $\mathrm{S}-\mathrm{N}$ curve and the effective distribution for all individual stress amplitudes. The accumulated fatigue damage rate is summed up from the fatigue damage arising in a set of individual sea states selected to represent the long-term environmental conditions. According to the Palmgren-Miner rule, the cumulative degree of fatigue damage is calculated by:

$\mathrm{D}=\sum \frac{\mathrm{n}_{\mathrm{i}}}{\mathrm{N}_{\mathrm{ti}}}$

In Eq. 33, $\mathrm{D}$ is the accumulated fatigue damage, $\mathrm{n}_{\mathrm{i}}$ is the number of stress cycles in the $\mathrm{i}^{\text {th }}$ stress block, and $\mathrm{N}_{\mathrm{ti}}$ is the number of cycles to failure under the constant stress range $\Delta \sigma$. The fatigue life is the reciprocal of accumulated fatigue damage:

$\mathrm{L}_{\text {Fatigue }}=\frac{1}{\mathrm{D}}$

The FLS is intended to ensure that each type of component in an individual mooring line has a suitable resistance to fatigue failure. Based on the recommendation of DNVGL-OS-E301, the design equation for the FLS is as follows:

$1-$ D. $\gamma_{\mathrm{f}} \geq 0$

In Eq. 35, $\gamma_{\mathrm{f}}$ is the single safety factor for fatigue limit state.

\section{RESULTS AND DISCUSSION}

An extensive parametric study was performed to determine the effect of the TLCD on a floating breakwater. A TLCD was coupled with a floating breakwater to evaluate the floating body response, fairlead displacement, mobilized tension, damage rate, and fatigue life of the mooring lines under irregular wave excitation. A fatigue analysis of the mooring lines was conducted for models of the floating breakwater with and without the TLCD (FB-TLCD and FB, respectively). For the results, the focus was on tradeoff between criteria that measure the mobilized tensile stress in mooring lines and fatigue damage rate induced by different sea states for FB and FB-TLCD.

\subsection{Description of Model}

A single rectangular pontoon floating breakwater installed in a water depth of $20 \mathrm{~m}$ was considered. The model of the floating breakwater consisted of a single rectangular pontoon and eight submerged mooring chains, as shown in Figs. 1 and 2. The total mass of the floating breakwater was $94,500 \mathrm{~kg}$. The principal dimensions of the floating breakwater are summarized in Table 2. The damping system comprised four identical TLCDs that were embedded in the void space inside the floating pontoon. The total length of the TLCD was $11 \mathrm{~m}$. Damping devices were uniformly distributed along the pontoon length. The key parameters of the TLCD are presented in Table 3. The mass of the TLCD, which was about $1 \%$ of the total mass of the floating breakwater, was $905 \mathrm{~kg}$. The R3 grade stud link chain was the component of the mooring system. The engineering specifications of this grade are extensively presented in DNVGLOS-E302. For R3 grade material, the yield stress and tensile strength are 410 and $690 \mathrm{MPa}$, respectively. The nominal diameter of each mooring line was $0.152 \mathrm{~m}$, the total length of each mooring line was $35 \mathrm{~m}$, and the transversal and longitudinal drag coefficients were set to 2.4 and 1.5 , respectively, for numerical simulations.

Table 2 Principal dimensions of the floating breakwater

\begin{tabular}{ccccc}
\hline $\boldsymbol{L}_{\boldsymbol{p}}(\boldsymbol{m})$ & $\boldsymbol{B}(\boldsymbol{m})$ & $\boldsymbol{H}(\boldsymbol{m})$ & $\boldsymbol{d}(\boldsymbol{m})$ & Total Mass $(\mathbf{K g})$ \\
\hline 20 & 6 & 4 & 20 & 94500 \\
\hline
\end{tabular}


The long-term environmental conditions of the Persian Gulf over 1 year was represented by 30 short-term sea states, which are described in Table 1. Each condition consisted of a reference sea state characterized by the significant wave height, peak wave period, and occurrence probability.

Table 3 Characteristics of tuned liquid column damper

\begin{tabular}{ccccccc}
\hline $\boldsymbol{A}_{v}\left(\boldsymbol{m}^{2}\right)$ & $\boldsymbol{A}_{\boldsymbol{h}}\left(\boldsymbol{m}^{2}\right)$ & $\boldsymbol{L}(\boldsymbol{m})$ & $\boldsymbol{h}(\boldsymbol{m})$ & $\boldsymbol{L}_{e f f}(\boldsymbol{m})$ & $\boldsymbol{d}_{\boldsymbol{A}}(\boldsymbol{m})$ & $\boldsymbol{\gamma}_{\boldsymbol{f}}\left(\boldsymbol{K} \boldsymbol{g} / \boldsymbol{m}^{3}\right)$ \\
\hline 0.02 & 0.02 & 5 & 3 & 11 & 2.5 & 1030 \\
\hline
\end{tabular}

\subsection{Mooring Line Peak Tension}

Preventing mooring line failure is a key design objective for floating breakwater systems. The mooring lines that are placed seaside of the floating body are subjected to the heaviest tension under wave action in the normal direction. Because of the symmetric arrangement of mooring lines in both the east-west and south-north directions, mooring lines S1 and S2 in Fig. 2 were evaluated, as discussed in this section. Figs. 11 and 12 show the variation in peak mobilized tension for various sea states as a function of the normalized wave frequency. The variation in the tension exhibited large values in the low frequency range, where resonance occurred and then gradually decreased.
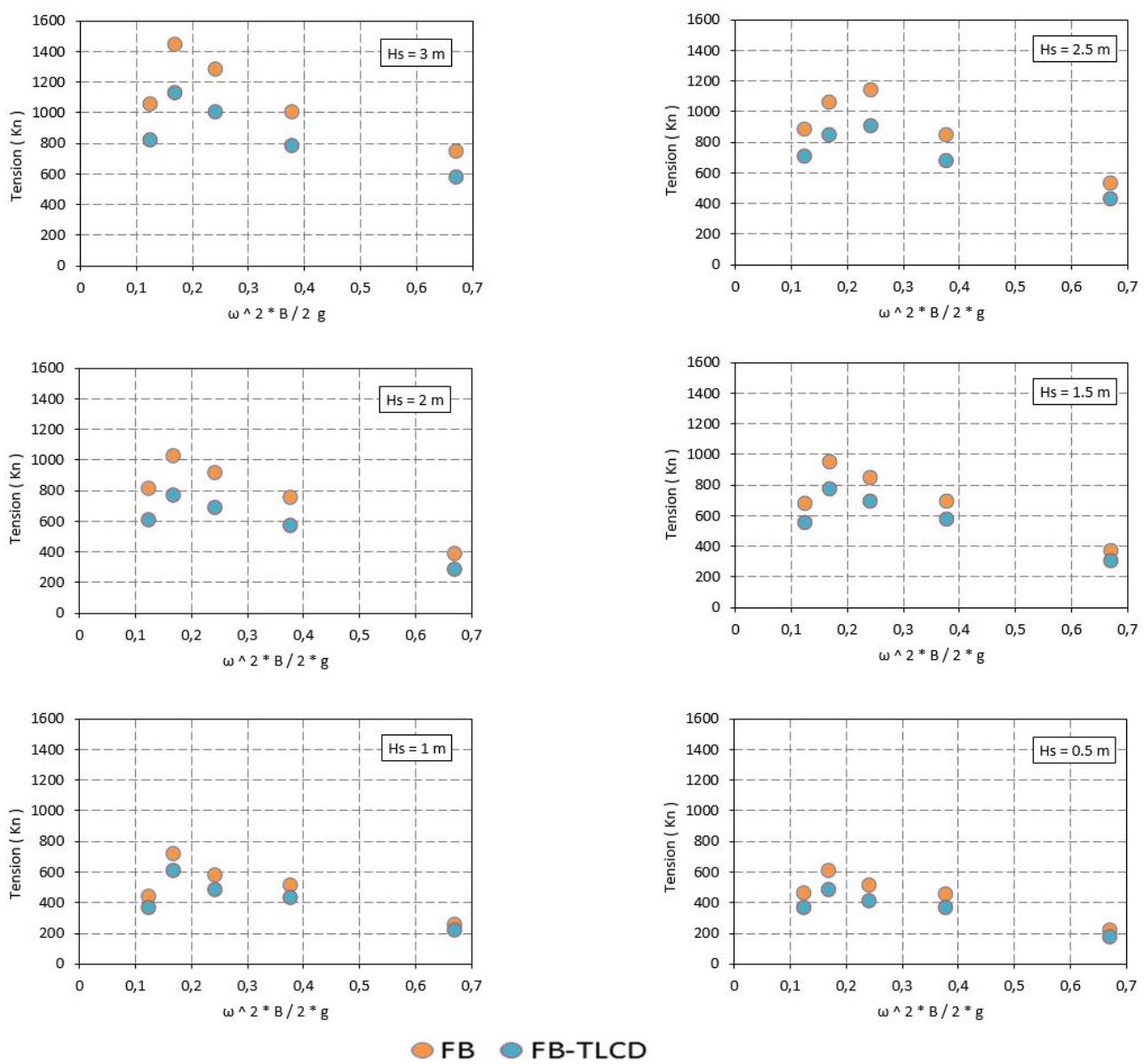

Figure 11 Variation of peak mobilized tension for S1 mooring line.

As shown in Figs. 11 and 12, the peak tension in the mooring lines decreased remarkably when supplementary control devices were added to the floating breakwater with reductions of approximately $26 \%$ for S1 and $24 \%$ for S2. As noted previously, reducing the mobilized tension in the mooring lines dramatically decreased the likelihood of the mooring system being damaged by fatigue. This would reduce the maintenance costs and increase the operational safety of the floating breakwater system. Note that the peak tensile stress was lower than the yield stress of the mooring lines for all sea states. At $\mathrm{Hs}=3 \mathrm{~m}$ and $\mathrm{Tp}=6 \mathrm{~s}$, the peak tensile stress in $\mathrm{S} 1$ was $80.1 \mathrm{MPa}$, which is less than the allowable tensile strength of the mooring lines. The same held for $\mathrm{S} 2$ at $\mathrm{Hs}=3 \mathrm{~m}$ and $\mathrm{Tp}=5 \mathrm{~s}$. The peak mobilized stress in this sea state was $135.5 \mathrm{MPa}$. 

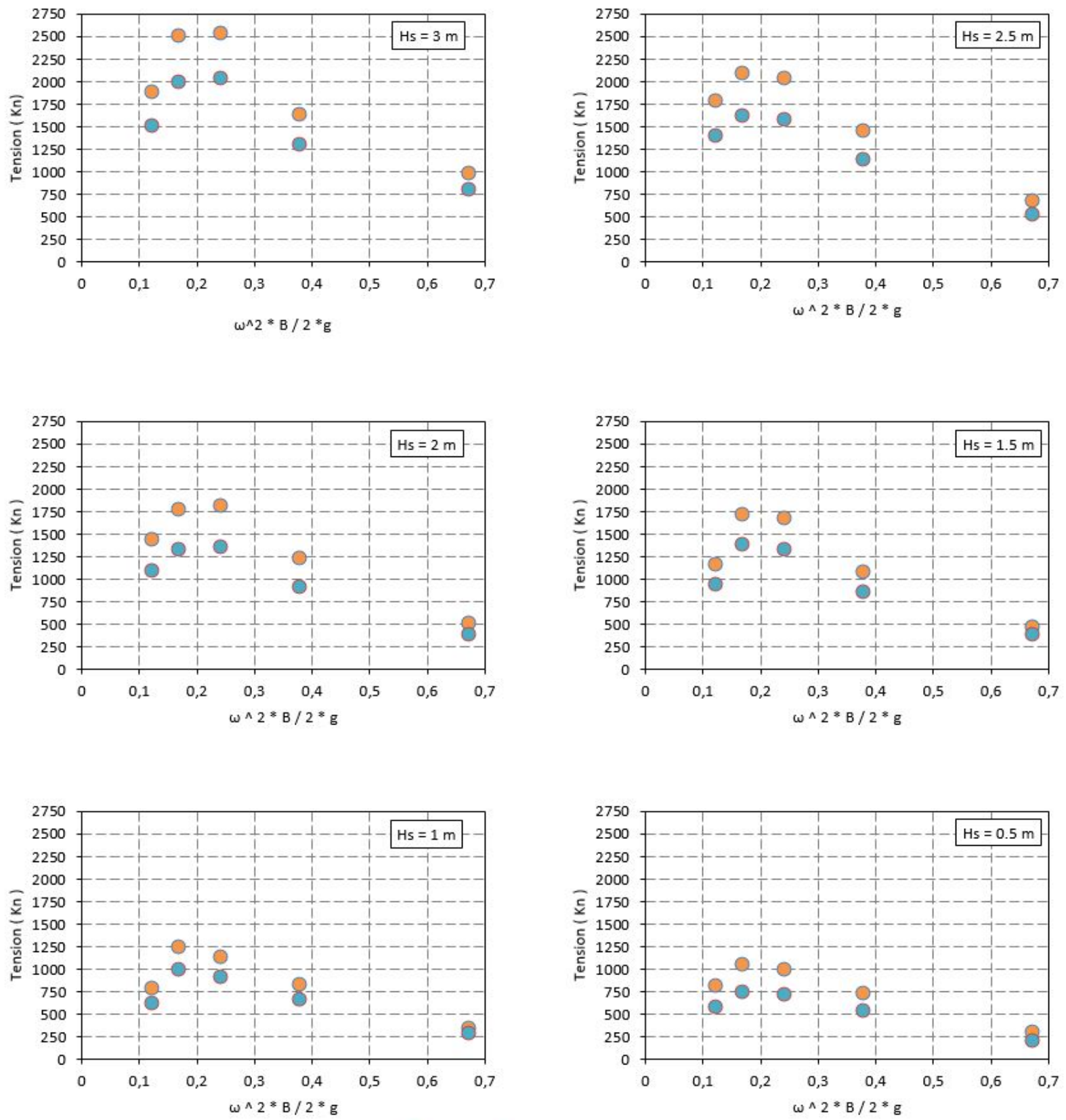

FB

FB-TLCD

Figure 12 Variation of peak mobilized tension for S2 mooring line

\subsection{Fairlead Displacement}

The influence of the TLCD on the displacement of the fairlead points for mooring lines S1 and S2 was considered. FB and FB-TLCD were investigated under the excitation of the No. 18 sea state, which was one of the strongest wave conditions with $\mathrm{Hs}=3 \mathrm{~m}$ and $\mathrm{Tp}=5 \mathrm{~s}$. The time history of the surface elevation, spectral density, and wave loads for the input sea state are plotted in Figs. 13-15. 


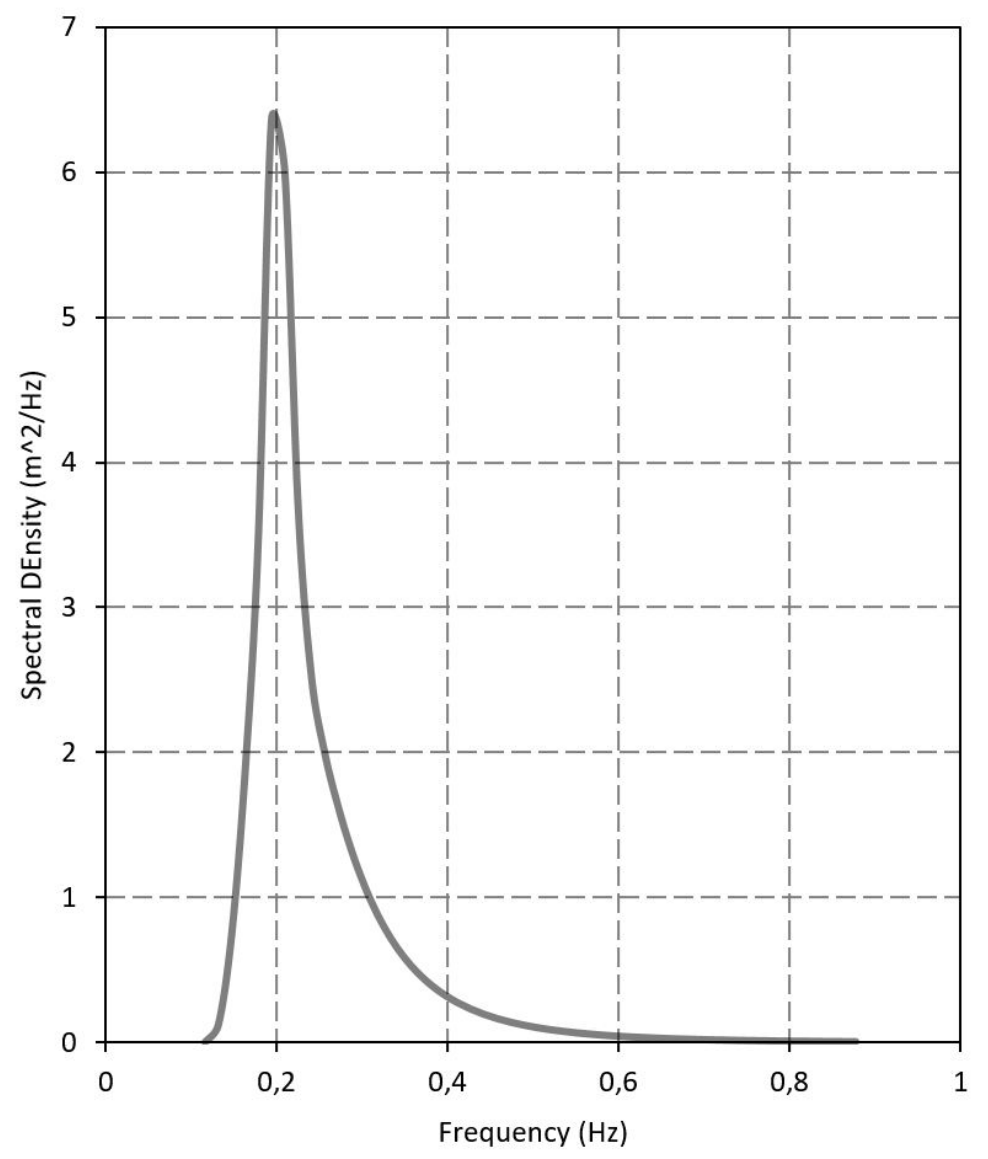

Figure 13 Power spectral density for sea state No. 18.

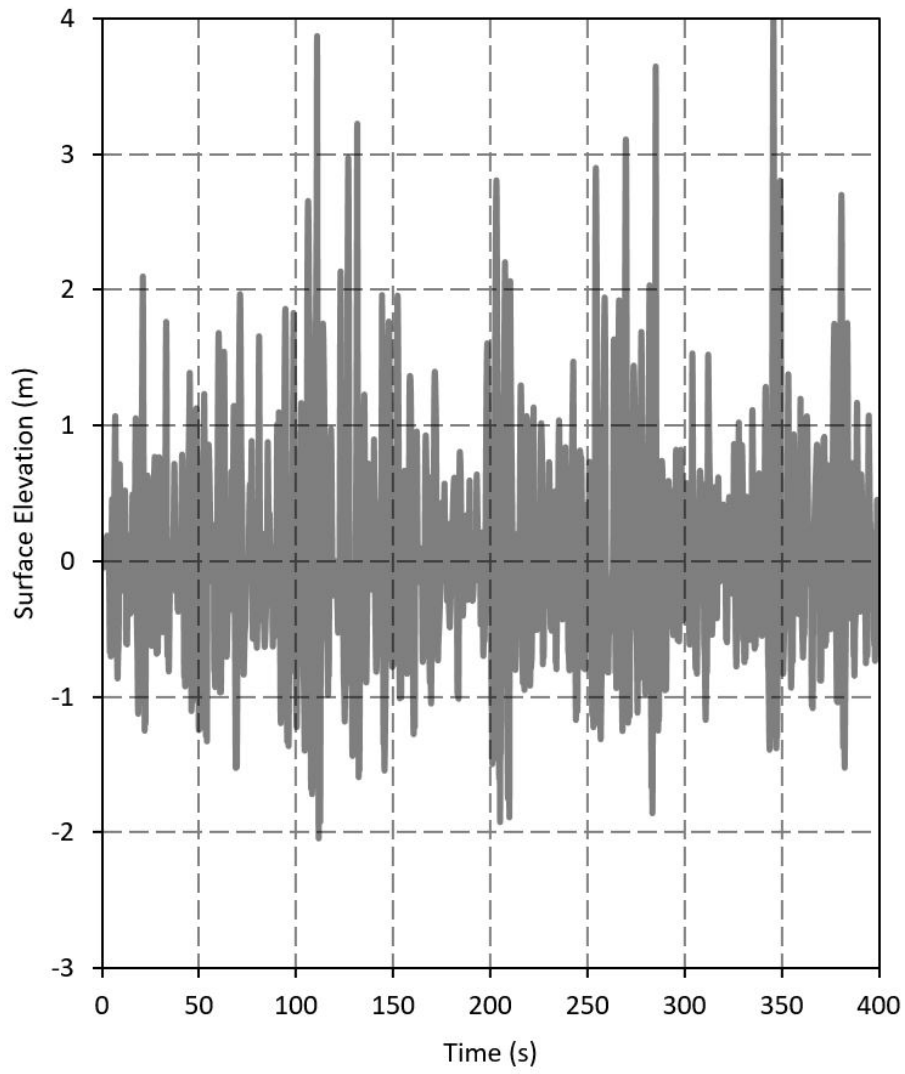

Figure 14 Time series for sea state No. 18. 
When the surface elevation increased or decreased, the wave load acting on the floating body changed accordingly. Fig. 16 presents the time history of the fairlead displacement for S1 and S2 subjected to the combined wave forces and moment plotted in Fig. 15. In the time segment presented, TLCD clearly reduced the peak displacement of the fairlead point by $31 \%$. FB had a peak displacement of $2.79 \mathrm{~m}$, while FB-TLCD had a displacement of $1.93 \mathrm{~m}$. Because the floating body was a solid box, the results for S1 and S2 can be generalized to the other fairlead points of the model. Further, the TLCD can be concluded to have successfully mitigated the overall motion of floating body and thus may lead to the better hydrodynamic performance.
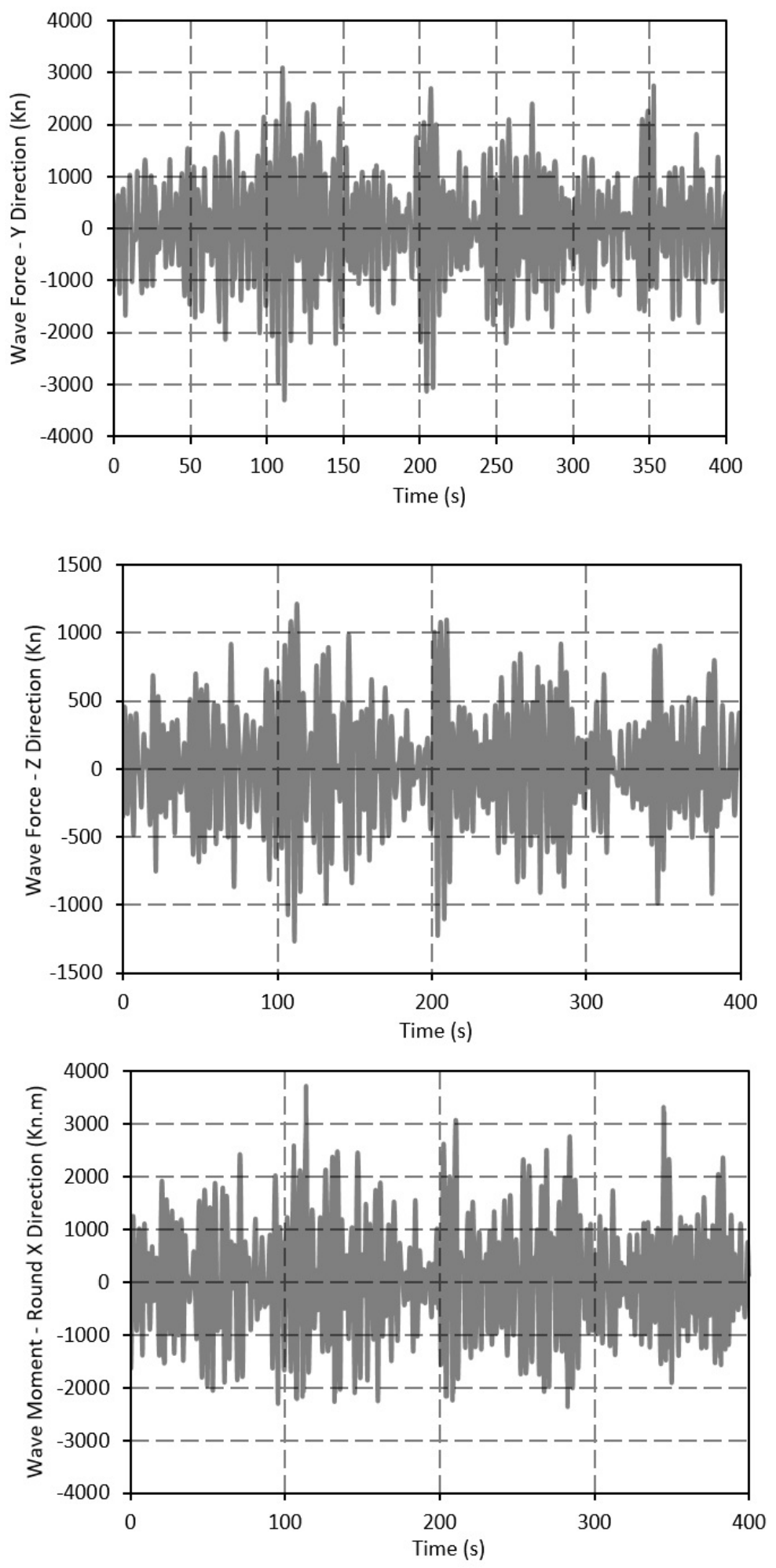

Figure 15 Wave force and moment for sea state No. 18. 


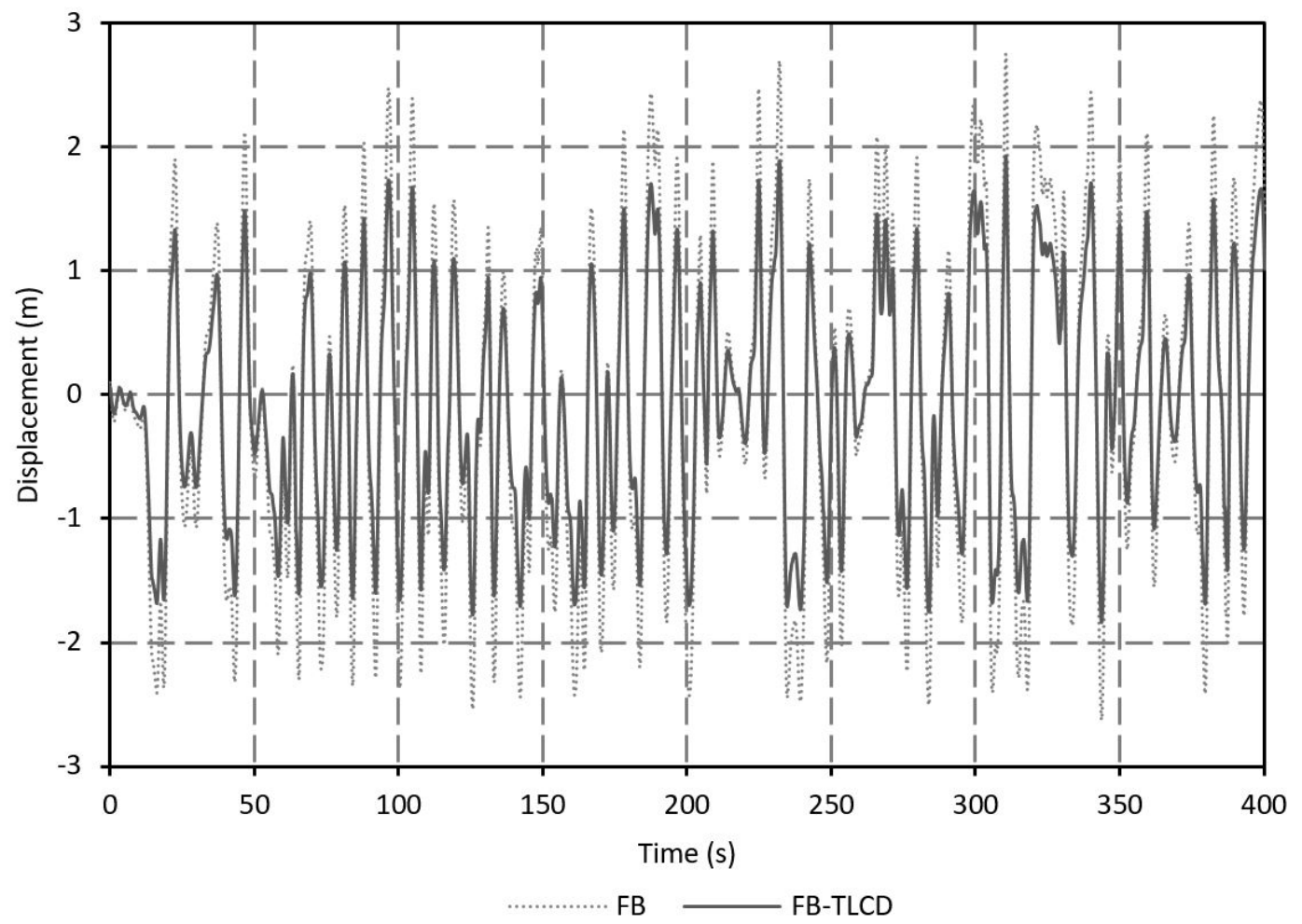

Figure 16 Displacement of fairlead for sea state No. 18.

\subsection{Fatigue Life}

The fatigue of the selected mooring lines was evaluated with the rainflow cycle counting method. Figs. 17 and 18 show the fatigue damage rates of mooring lines S1 and S2 for FB and FB-TLCD. The results clearly showed that the TLCD reduced the damage rate for each sea state. Table 4 presents the accumulated damage rate for $\mathrm{S} 1$ and $\mathrm{S} 2$ caused by all sea states. As shown in Fig. 19(a), the cumulative fatigue damage rate was reduced by 36\% for S1 and 31\% for S2 with the TLCD.

Table 4

Comparisons of accumulated fatigue damage rate for floating breakwater with and without TLCD

\begin{tabular}{cccc}
\hline Case & $\boldsymbol{F B}$ & $\boldsymbol{F B}-\boldsymbol{T L C D}$ & Difference $(\%)$ \\
\hline S1 Mooring Line & $2.26 \mathrm{E}-03$ & $1.45 \mathrm{E}-03$ & -36.06 \\
S2 Mooring Line & $2.31 \mathrm{E}-03$ & $1.59 \mathrm{E}-03$ & -30.69 \\
\hline
\end{tabular}

Table 5 summarizes the computed fatigue lives and safety factors for S1 and S2. The mooring lines for FB-TLCD had considerably longer fatigue lives than FB. The fatigue life of S1 increased by 56\% to 691 years with FB-TLCD compared to 441 years with FB. Likewise for S2, the fatigue life increased by $44 \%$ to 627 years with FB-TLCD compared to 434 years with FB. The material mechanical properties and cyclic environmental loads are two primary factors that affect the fatigue life of a mooring line. While the mechanical properties of materials are intrinsic characteristics, the applied environmental loads describe an extrinsic process. Although employing a high-strength material is a feasible solution to improving the fatigue strength of mooring lines, this would impose additional costs on the mooring system. The results presented in this section prove that the TLCD can be used as an alternative solution to improve the fatigue life of mooring lines.

Table 5

Comparisons of fatigue life for floating breakwater with and without TLCD

\begin{tabular}{cccc}
\hline Case & FB & FB - TLCD & Difference (\%) \\
\hline S1 Mooring Line & 441 & 691 & +56 \\
S2 Mooring Line & 434 & 627 & +44 \\
\hline
\end{tabular}



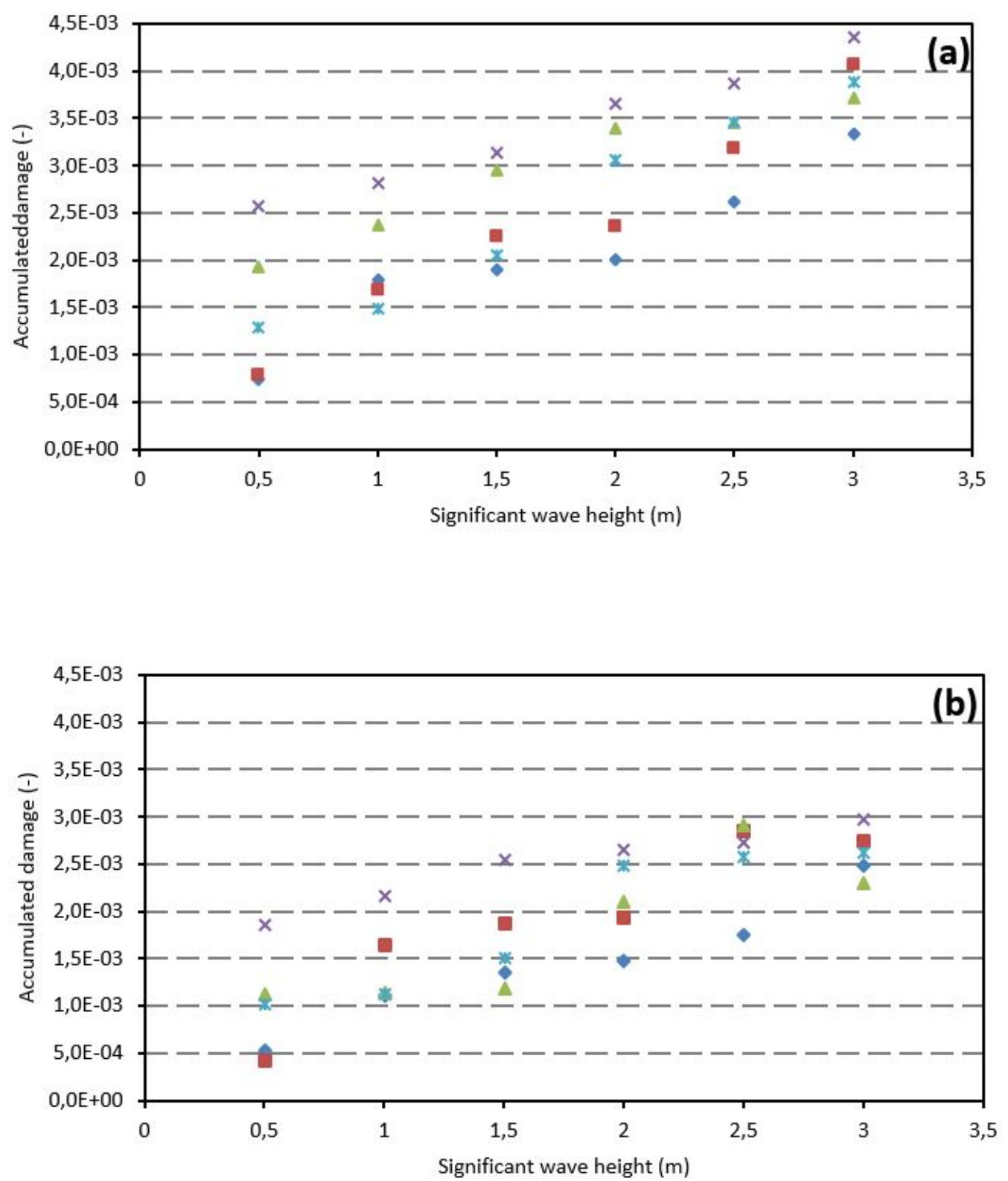

- $T p=3 s \quad=T p=4 s \quad \therefore T p=5 s \quad \times T p=6 s \quad * T p=7 s$

Figure 17 Fatigue damage of S1 mooring line for: (a) FB, (b) FB-TLCD. 

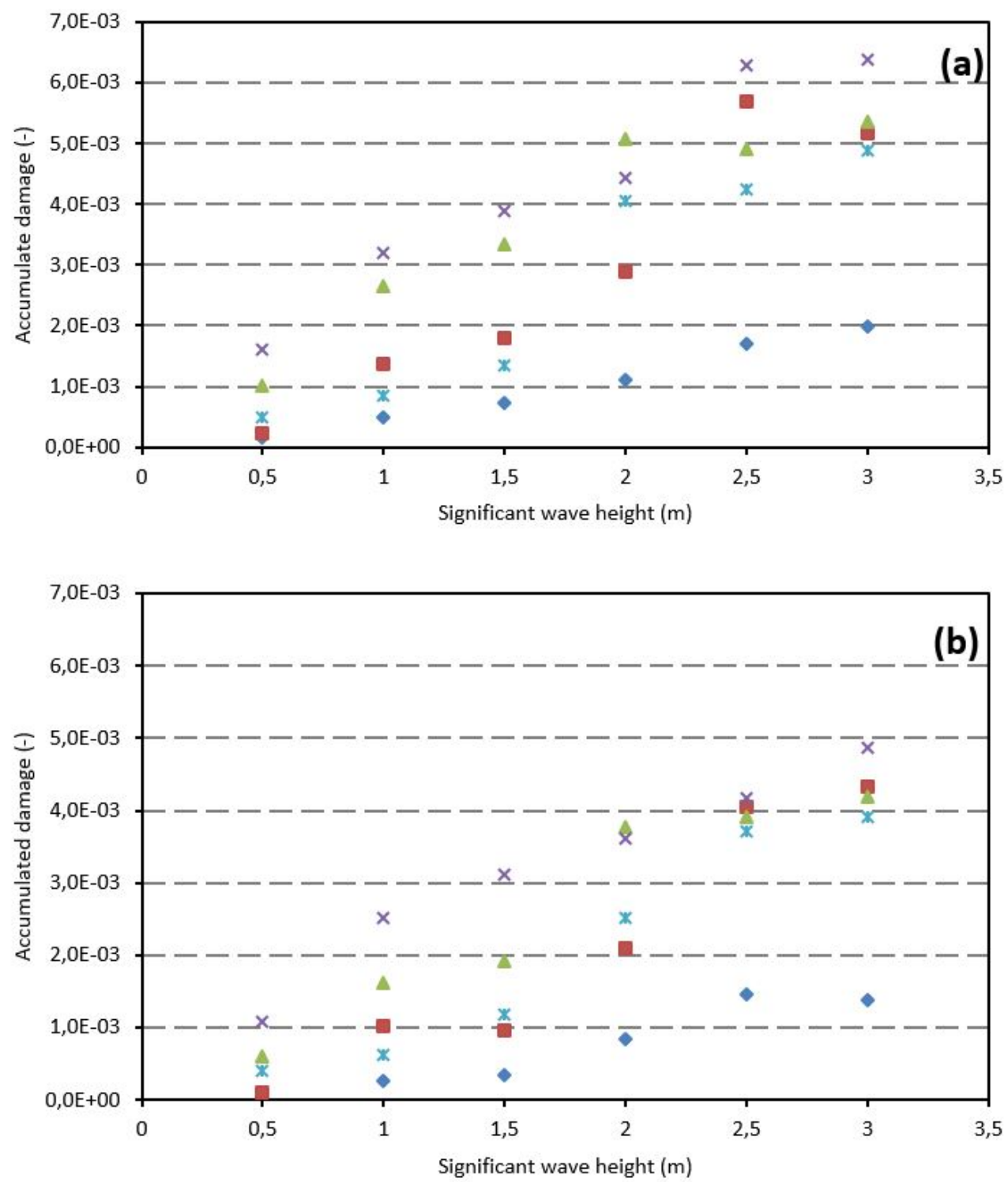

Figure 18 Fatigue damage of S2 mooring line for: (a) FB, (b) FB-TLCD.
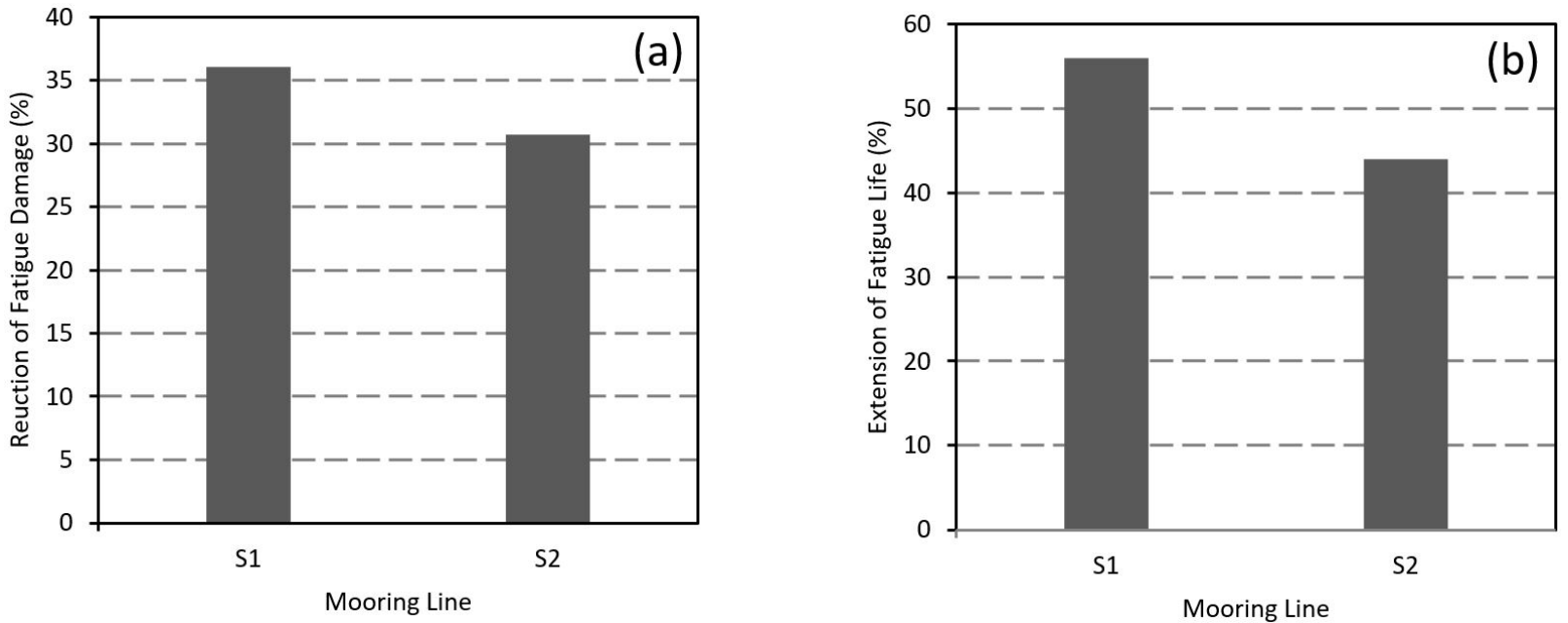

Figure 19 (a) Percentage of reduction for fatigue damage, (b) Percentage of extension for fatigue life. 


\section{CONCLUSION}

The potential of the TLCD to enhance the fatigue life of a floating breakwater was investigated analytically and numerically. First, a floating breakwater model was created with the ANSYS AQWA Hydrodynamic module. The model responses were validated by comparison with the measured data of experimental investigations. Then, the behavioral equations of the TLCD were derived. The joint FB-TLCD model was developed through an iterative coupling procedure. Mooring lines were evaluated for cases with and without the TLCD. FB-TLCD reduced the peak mobilized tensile stress in the mooring lines by up to $26 \%$ compared to FB. This result can be used by offshore engineers to design mooring systems more efficiently with less steelwork and lower foundation expenses. The benefits of the TLCD in terms of mitigating the responses of the floating body and displacement of the mooring line fairlead position were also demonstrated.

The S-N curve approach was employed for the fatigue assessment. The fatigue lives of the mooring lines were calculated by combining the Palmgren-Miner rule and rainflow cycle counting method. The results indicated that the TLCD increased the fatigue life of mooring lines. This result ensures the operational safety of a floating breakwater equipped with a TLCD. In addition, the presented case study showed that the failure probability of mooring lines against fatigue damage was also reduced and was acceptable for the safety factor defined in DNVGL-OS-E301. This proposed approach of applying a TLCD is a practical tool for designing the components of a floating breakwater more efficiently.

Author's Contributions: Investigation and Writting, M Shahrabi; Supervision, K Bargi.

Editor: Marcílio Alves.

\section{References}

Ansys V.17.2, (2016). Ansys: theory manual. Southpointe, 275 Technology Drive, Canonsburg, PA 15317: ANSYS, Inc.

Bargi, K., Dezvareh, R., \& Mousavi, S.A., 2016. Contribution of tuned liquid column gas dampers to the performance of offshore wind turbines under wind, wave, and seismic excitations. Earthquake Engineering and Engineering Vibration, 15(3), 551-561. Doi: https://doi.org/10.1007/s11803-016-0343-z

Colwell, S., Basu, B., 2009. Tuned liquid column dampers in offshore wind turbines for structural control. Engineering Structures, 31(2), 358-368. Doi: https://doi.org/10.1016/j.engstruct.2008.09.001

Coudurier, C., Lepreux, O., Petit, N., 2018. Modeling of a tuned liquid column damper. Application to floating wind turbine for improved robustness against wave incidence. Ocean Engineering, 165, 277-292. Doi:

https://doi.org/10.1016/j.oceaneng.2018.03.033

De Laval, G., 1971. Fatigue tests on anchor chain cable. In: Proceedings of Offshore Technology Conference, OTC 1503. Dallas, Texas, USA.

Dezvareh, R., Bargi, K., \& Mousavi, S.A., 2015. Control of wind/wave-induced vibrations of jacket-type offshore wind turbines through tuned liquid column gas dampers. Structure and Infrastructure Engineering, 12(3), 312-326. Doi: https://doi.org/10.1080/15732479.2015.1011169

DNVGL OS E301, 2017. Offshore Standard DNVGL-OS-E301: Position Mooring. Det Norske Veritas and Germanischer Lloyd SE.

Dong, G.H., Zheng, Y.N., Li, Y.C., Teng, B., Guan, C.T., Lin, D.F., 2008. Experiments on wave transmission coefficients of floating breakwaters. Ocean Engineering, 35, 931-938. Doi: https://doi.org/10.1016/j.oceaneng.2008.01.010

Gao, Z., Moan, T., 2007. Fatigue damage induced by non-Gaussian bimodal wave loading in mooring lines. Applied Ocean Research, 29, 45-54. Doi: https://doi.org/10.1016/j.apor.2007.06.001

Gesraha, M.R., 2006. Analysis of the $\pi$ shaped floating breakwater in oblique waves: Impervious rigid boards. Applied Ocean Research, 28(5), 327-338. Doi: https://doi.org/10.1016/j.apor.2007.01.002

Ha, M., Cheong, C., 2016. Pitch motion mitigation of spar-type floating substructure for offshore wind turbine using multilayer tuned liquid damper. Ocean Engineering, 116, 157-164. Doi: https://doi.org/10.1016/j.oceaneng.2016.02.036 
Hemmati, A., Oterkus, E., Khorasanchi, M., 2019. Vibration suppression of offshore wind turbine foundations using tuned liquid column dampers and tuned mass dampers. Ocean Engineering, 172, 286-295. Doi: https://doi.org/10.1016/j.oceaneng.2018.11.055

Horde, G.O., Moan, T., 1997. Fatigue and overload reliability of mooring systems. In: Proceedings of the Seventh International Offshore and Polar Engineering Conference. International Society of Offshore and Polar Engineers. Honolulu, Hawaii, USA.

Hou, H.M., Dong, G.H., Xu, T.J., Zhao, Y.P., Bi, C.W., Gui, F.K., 2018. Fatigue reliability analysis of mooring system for fish cage. Applied Ocean Research, 71, 77-89. Doi: https://doi.org/10.1016/j.apor.2017.12.008

Jaksic, V., Wright, C., Chanayil, A., Ali, S.F., Murphy, J., Pakrashi, V., 2015. Performance of a single liquid column damper for the control of dynamic responses of a tension leg platform. Journal of Physics: Conference Series, 628. Doi: https://doi.org/10.1088/1742-6596/628/1/012058

Ji, C.Y., Chen, X., Cui, J., Yuan, Z.M., Incecik, A., 2015. Experimental study of a new type of floating breakwater. Ocean Engineering, 106, 295-303. Doi: https://doi.org/10.1016/j.oceaneng.2015.06.046

Kvitrud, A., 2014. Lessons learned from the Norwegian mooring failures 2010-2013. In: Proceedings of the ASME 2014 33rd International Conference on Ocean, In: Offshore and Arctic Engineering. OMAE 2014-23095. San Francisco, California, USA.

Lackner, M.A., Rotea, M.A., 2011. Structural control of floating wind turbines. Mechatronics, 21(4), 704-719. Doi: https://doi.org/10.1016/j.mechatronics.2010.11.007

Lassen, T., Syvertsen, K., 1997. Fatigue reliability and life-cycle cost analysis of mooring chains. International Journal of Offshore and Polar Engineering, 7 (2), 135-140.

Lee, H.H., Juang, H.H., 2012. Experimental study on the vibration mitigation of offshore tension leg platform system with UWTLCD. Smart Structures and Systems, 9, 71-104.

Lee, H.H., Wong, S.H., Lee, R.S., 2006. Response mitigation on the offshore floating platform system with tuned liquid column damper. Ocean Engineering, 33 (8-9), 1118-1142. Doi: https://doi.org/10.1016/j.oceaneng.2005.06.008

Lereim, J., 1985. Summary of the 4-year research project: anchor chain cables offshore. In: Proceedings of 17th Offshore Technology Conference. Houston, Texas, USA.

Loukogeorgaki, E., \& Angelides, D.C., 2005. Stiffness of mooring lines and performance of floating breakwater in three dimensions. Applied Ocean Research, 27(4-5), 187-208. Doi: https://doi.org/10.1016/j.apor.2005.12.002

Loukogeorgaki, E., Yagci, O., \& Kabdasli, M.S., 2014. 3D Experimental investigation of the structural response and the effectiveness of a moored floating breakwater with flexibly connected modules. Coastal Engineering, 91, 164-180. Doi: https://doi.org/10.1016/j.coastaleng.2014.05.008

Ma, K.T., Duggal, A., Smedley, P., L'Hostis, D., Shu, H., 2013. A historical review on integrity issues of permanent mooring systems. In: Offshore Technology Conference, OTC 24025. Houston, Texas, USA.

Mousavi, S.A., Zahrai, S.M., \& Bargi, K., 2012. Optimum geometry of tuned liquid column-gas damper for control of offshore jacket platform vibrations under seismic excitation. Earthquake Engineering and Engineering Vibration, 11(4), 579-592. Doi: https://doi.org/10.1007/s11803-012-0143 z

Nijssen, R.P.L., 2006. Fatigue life prediction and strength degradation of wind turbine rotor blade composites. Sandia National Laboratories. Delft University of Technology.

Olagnon, M., Guede, Z., 2008. Rainflow fatigue analysis for loads with multimodal power spectral densities. Marine Structures, 21, 160-176. Doi: https://doi.org/10.1016/j.marstruc.2007.12.004

Reiterer, M., Ziegler, F., 2006. Control of pedestrian induced vibrations of long-span bridges. Structural Control and Health Monitoring, 13, 1003-1027. Doi: https://doi.org/10.1002/stc.91

Roderick, C., 2012. Vibration reduction of offshore wind turbines using tuned liquid column dampers (Master's Thesis, University of Massachusetts Amherst).

Sakai, F., Takaeda, S., Tamaki, T., 1989. Tuned liquid column damper - new type device for suppression of building vibration. In: Proceedings of International Conference on High-rise Buildings, 926-931. Nanjing, China.

Sannasiraj, S.A., Sundar, V., \& Sundaravadivelu, R., 1998. Mooring forces and motions responses of pontoon-type floating breakwaters. Ocean Engineering, 25(1), 27-48. Doi: https://doi.org/10.1016/S0029-8018(96)00044-3 
Schutz, W., 1996. A history of fatigue. Engineering Fracture Mechanics, 54 (2), 263-300. Doi: https://doi.org/10.1016/00137944(95)00178-6

Shahrabi, M., Bargi, K., 2013. Numerical simulation of multi body floating piers to investigate pontoon stability. Frontiers of Structural and Civil Engineering, 7, 325-331.

Thies, P.R., Johanning, L., Harnois, V., Smith, H.C.M., Parish, D.N., 2014. Mooring line fatigue damage evaluation for floating marine energy converters: field measurements and prediction. Renewable Energy, 63, 133-144. Doi: https://doi.org/10.1016/j.renene.2013.08.050

Van Helvoirt, L.C., 1982. Static and fatigue tests on chain links and chain connecting links. In: Proceedings of Offshore Technology Conference, OTC 4179. Houston, Texas, USA.

Williams, A.N., Abul-Azm, A.G., 1997. Dual pontoon floating breakwater. Ocean Engineering. 24 (5), 465-478. Doi: https://doi.org/10.1016/S0029-8018(96)00024-8

Williams, A.N., Lee, H.S., Huang, Z.A., 2000. Floating pontoon breakwaters. Ocean Engineering. 27 (3), 221-240. Doi: https://doi.org/10.1016/S0029-8018(98)00056-0

Xu, T.J., Zhao, Y.P., Dong, G.H., Bi, C.W., 2014. Fatigue analysis of mooring system for net cage under random loads. Aquacultural Engineering, 58, 59-68. Doi: https://doi.org/10.1016/j.aquaeng.2013.10.004

Xue, X., Chen, N.Z., Wu, Y., Xiong, Y., Gou, Y., 2018. Mooring system fatigue analysis for a semi-submersible. Ocean Engineering, 156, 550-563. Doi: https://doi.org/10.1016/j.oceaneng.2018.03.022 